\title{
Crystal-morphology and Evolution of Snow Cover: Empirical Modeling on the Base of Symmetry Theory
}

\author{
Erland. G. Kolomyts ${ }^{1}$ \\ ${ }^{1}$ Institution of Ecology of the Volga River Basin, Russian Academy of Sciences, D-2-82, Pushchino, \\ Moscow region, Russia \\ Correspondence: Erland. G. Kolomyts, Institution of Ecology of the Volga River Basin, Russian Academy of \\ Sciences, D-2-82, Pushchino, Moscow region 142290, Russia. E-mail: egk2000@mail.ru
}

Received: September 2, 2012 Accepted: October 14, 2012 Online Published: October 25, 2012

doi:10.5539/jgg.v4n4p123 URL: http://dx.doi.org/10.5539/jgg.v4n4p123

\begin{abstract}
Snow cover is represented as a natural community of the shapes of growing crystals interacting with each other and exposed to environmental influences. It is worked out the empirical deterministic models describing the sublimation-metamorphic cycle of seasonal snow cover and the polymorphic variants of this cycle. The main driving force of processes yielding an evolutionary row of crystals are internal interactions within a snow pack. For all that the factor of time (the age of genetic player) plays a crucial role in sublimation metamorphism. Stadiality of the forms of crystal growth and self-development snow layers are revealed. They are a result of successive process of superposition of ice crystal-chemical symmetry and dissymmetry of the whole system soil-snow-atmosphere, according to the known P. Curie principle.

Crystal-morphological classification for season snow is worked out by author on the base of the given an account evolutionary model. Two categories of crystal shapes have been picked out: classes and types of forms. The first category reflects the invariant aspect of snow sublimation metamorphism and the second one - the hydrothermal conditions of this process in each layer of the snow pack.

Evolution of snow pack structure is conditioned to a marked degree by probabilistic conformity to natural laws, manifesting themselves in the processes of auto-regulation of metamorphism. These processes include the two types of regulation: the self-regulation of snow layers, on the one hand, and their regulation from outside - under the influence of atmospheric perturbations, on the other hand. An analysis of the processes of auto-regulation of metamorphism is capable of rendering a substantial service in the development of methods of short- and long-term forecasting of the avalanches. Crystal-morphological structure of snow cover may be considered also as a "quickly running" model of many evolutionary biosphere processes.
\end{abstract}

Keywords: snow cover, structure, crystal-morphology, symmetry theory, evolution, classification

\section{Introduction}

Up to the present, the study of processes within snow packs has been based on consideration of snow cover mainly as a continual matter-energy system. It has already become a tradition to phenomenological approach (according to classic thermodynamic) - to interpret snow on the ground as a three-component porous material capable of irreversible viscous deformations (Watanabe, 1980; Brown \& Edens, 1991; Edens \& Brown, 1991; Golubev \& Frolov, 1998) and reflecting the winter hydro-meteorological conditions (Colbeck, 1982; Durand, et al., 1993; Bartelt, Buser \& Sokratov, 2002; Lehning, Bartelt, Brown, \& Fierz, 2002; Sokratov \& Barry, 2002; Sokratov \& Troshkina, 2009). In this respect, the most important physical-mechanical properties of snow have been studied completely enough (Gray \& Male, 1981; Pielmeier \& Scheebeli, 2003). Their mathematical models have been developed, which are of great theoretical and applied significance, first of all, for prediction of snow avalanches (Brun, David, Sudul, \& Brunot, 1992; Durand, Brun, \& Merindol, 1993; Bartelt \& Lehnening, 2002; Bozhinsky, Nazarov, \& Chernous, 2002; Lehning, Bartelt, Brown, \& Fierz, 2002). The systems of classification by the character and degree of avalanche hazard have been developed for the mountain territories of the former USSR on the basis of coupled analysis of geophysical processes and geographical avalanche-formation factors (Bozhinsky \& Losev, 1978).

At the same time, in most of the snow studies (both in Russia and abroad) the methods of contemporary 
crystal-morphology are still insufficiently employed in structural snow science and avalanche science, thus to some extent retarding further development of these branches of glaciology. It is true that the modern studies into the structure of snow cover consider it as a heterogeneous environment varying in time in its structural and stratigraphic characteristics (Sokratov, 2001; Bartelt, Lehning, 2002; Chernov, 2003; Kaempfel, Sokratov, \& Schneebeli, 2004; Schneebli \& Sokratov, 2004). However, here it is necessary to search for regularities of these variations and to establish the mechanisms controlling evolutionary transformations of snow structures. The question of the extent to which the sublimation metamorphism of deposited snow is a process of its self-development, i.e., a really evolutionary process in the strict scientific sense of this term (Timofeev-Resovsky, Vorontcov, Yablokov, 1969; Odum, 1983), is still open. What is meant here is directional structural changes in a given natural system, first, from simple to complex and, second, on the basis of primarily internal interactions in the system, against the background of its adaptation to variable environment.

In the very beginning of snow cover studies in the regions of Siberia and Far East the author (Kolomyts, 1976) encountered the poor information that could be obtained using already established methods of field structure analysis of seasonal snow. Snow cover is first of all a crystalline body, and hence the processes of its metamorphism obey the basic laws of crystallography (Vernadsky, 1965; Shafranovsky, 1968, Shubnikov, 1975; Yushkin, 1977) which unfortunately are little employed by glaciologists in analyzing snow structure in the field and in interpreting the data obtained. At the same time one can derive only very limited data on the processes occurring in the snowpack using generally accepted methods of structural analysis of snow sections in nature. That is way common snow structure analysis are usually based on the methods of granulometry (Seligman, 1936; Brown \& Edens, 1991; Brun, David, Sudul, \& Brunot, 1992; Golubev \& Frolov, 1998; etc), while the forms of crystals are considered as the essential but not main structural-stratigraphic property of snow cover (Schaefer, Klein, \& de Quervain, 1954; Gray \& Male, 1981; Colbeck, et al., 1990; Bartelt \& Lehning, 2002). Last "International Classification for Seasonal Snow on the Ground" (Fierz et al., 2009) has made essentially step forwards as compared with the previous classifications (Schaefer, Klein, \& de Quervain, 1954; Sommerfels \& La Chapelle, 1970; Colbeck, Akitaya, \& Armstrong, 1990) in respect of further equipment of methodical arsenal for the field structure research of snow cover.

The term "evolution of snowpack" is used pretty often (Colbeck, 1982; Lehning, Bartelt, Brown, \& Fierz, 2002; Pielmeier \& Schneebeli, 2003; Kaempfer, Sokratov, \& Schneebeli, 2004; Sokratov \& Troshkina, 2009; etc), however it has no particular meaning so far. It is still unclear to what extent the metamorphism of packed snow is a process of its self-development, i.e., a really evolutionary process, in the strict scientific meaning of this term. In the meantime, the whole history of West-European and Russian snow studies (Paulke, 1934; Seligman, 1936; Tushinsky, Gusykova, \& Gubareva, 1953; Sommerfeld \& La Chapelle, 1970; Gray \& Male, 1981; Kolomyts, 1976, 1977, 1984; Colbeck, 1982) shows that under some or other winter conditions snow cover is transformed from disordered pile of snow crystals deposited from the atmosphere into something integral, ordered, organized, i.e., creates itself as a certain glaciosystem. It may be a priori affirmed that the theory of evolution is fully applicable to metamorphic transformations of seasonal snow cover.

The morphology of snow crystals is studied mainly by means of laboratory experiments and observations of their individual free growth and morphogenesis (Tushinsky, Gusykova, \& Gubareva, 1953; Nakaya, 1954; Kobayashi, 1957; Yosida, 1960; Brown \& Edens, 1991), which substantially helps interpret the results of on-site observations. However, it is very difficult to reproduce in laboratory conditions the full nature diversity of evolutionary metamorphism processes in snow cover.

The centuries-old experience of establishment of the evolution theory in biology has shown that only discrete objects (individuals, species) and their system-forming combinations (populations, communities) as discrete qualitatively definite formations can evolve, but not some continual characteristics of individuals, populations and communities. In snow cover, such qualitative definiteness is typical only of crystal forms and a kind of their communities but in no way of grain sizes, parameters of grain contacts, surface energy, etc. (i.e., not granulometric characteristics). Grains cannot evolve (in the strict sense of this term) by definition. We believe that if it is excluded from consideration such a most important structural characteristic as the form of growing or evaporating crystals embodying the most structural quality of snow, then it makes no sense to speak about snow cover evolution as a directional process of its metamorphism.

Thus, glaciological engineering so far has not a sufficiently elaborated scientific and methodical basis for predicting the whole class of avalanches of according to terminology (Tushinsky, Gusykova, \& Gubareva, 1953), or, avalanches of prolonged development, by definition (Bozhinsky \& Losev, 1978), associated mainly with the evolutionary processes of metamorphism in snow cover. 
It is necessary to elaborate an evolutionary basis of the theory of sublimation metamorphism of seasonal snow cover for improvement of the scientific and methodical basis of snow avalanche prediction and development of the methods of indication of the winter regime of landscapes by snow structure. Solution of this problem is envisaged by way of constructing discrete models of system organization and development of snow cover based on its crystal morphology and fundamental laws of natural symmetry, as well as developing on the basis of these models the methods for investigation of the processes of sublimation snow metamorphism from positions of the theory of evolution. This theory, formed within biological sciences (Timofeev-Resovsky, Vorontcov, \& Yablokov, 1969), has been effectively applied to crystallography and genetic mineralogy (Sheftal, 1961; Shafranovsky, 1968, 1974; Shubnikov, 1975; Yushkin, 1977), as snow cover is a monomineral rock (Rikhter, 1955). It should be proved that the transformation of evolutionary units of snow cover (forms of crystals and their communities) is based on their self-development (self-organization and auto-regulation), which has both invariant and stochastic regularities, as well as the properties of adaptation to the varying winter meteorological regime. All these characteristics of snow cover sublimation metamorphism correspond to the propositions of the general theory of evolution of natural systems. Recent three-measured investigations of snow microstructure (Schneebeli, Sokratov, 2004) represent the doubtless interest in this aspect.

\section{Starting Position for the Evolutionary Snow Studies}

By the author's earnest conviction, evolutionary snow studies must be based on the probabilistic-statistical approach considering snow cover as a hierarchically organized system of discrete crystal spaces as interpreted by Vernadsky (1965). This system is based on the key structural property of snow: the shapes of growing crystals that reflect the whole complex of internal transformations of deposited snow. We postulate that snow cover is the system of natural assemblages of crystal forms, what in sometimes sense are analogous to the communities of individuals with different quality in living nature, according to definition (Shafranovsky, 1968). New snow crystals grow in a close mutual interaction and simultaneously experience the outside regulatory control, first of all from the atmosphere. With such approach, the analysis of snow structure and morphology must be based on the methods of crystal-morphology and fundamental laws of natural symmetry.

The basic law of crystallography states that crystal forms represent the processes of heat and moisture transfer in the medium surrounding them, and all conformity to natural laws of the growth of real crystals in essence characterize their divergence from the equilibrium state conforming to the internal (crystal-chemical) structure of the given material. This concerns the staged adaptation of a growing symmetrical single crystal to an dissymmetric medium - according to the well-known principle of the superposition of symmetries of P. Curie (1908), which is regarded as symmetric interpretation of the second law of thermodynamics (Shubnikov \& Koptcik, 1972). The principle of superposition of two symmetries, that is leave traces on each other, in the most general form appears as:

$$
\text { phenomenon }(\text { effect })=\text { characteristic } \times \text { action }
$$

In accordance with Curie's principle, snow structure development is a process irreversible in time, which consists of successive stages of superposition (overlap) of hexagonal and trigonal symmetry of ice as a mineral (genotype) and dissymmetry of the vector hydrothermal field of snowpack, as well as the field of relaxation of mechanical stress in the latter. It results in formation of a genetically integral chain of real ("forced", false) crystal forms (phenotypes) as a way of adaptation of growing crystals to environment (Sheftal, 1961; Shafranovsky, 1968; Sheftal \& Kolomyts, 1973).

\section{Objects and Methods}

Stationary observations of snow structure and hydrothermal regime were made on experimental plots in winters 1966/1967-1969/1970 in the middle plain taiga of West Siberia and in winter 1976/1977 in the low-mountain taiga of the Lower By-Amur (see below, Figure 9). The information was registered during winter in on and the same snow sections with an interval of about one month. At the end of winter seasons of the same years, the route studies of snow structure were performed in different plain and mountain regions of Russia: from extracontinental to suboceanic.

Based on the known concepts of the laws of real crystallization (Honigman, 1958; Sheftal, 1961, 1973; Shafranovsky, 1968, 1974; Yushkin, 1977), the forms of crystal growth and destruction were determined for each genetic layer of snow pack. Multiple determinations of crystal shapes and particle measurements were performed at a 5-10-fold optical magnification within the accuracy of $0.1 \mathrm{~mm}$. The statistical analysis of empirical material has shown that the probability of the final result varies within $70-75 \%$ per each snow sample for $200-300$ measurements, i.e., quite permissible accuracy for field studies. 
The following numerical parameters of snow structure were obtained: the average radius and volume of crystals, the percentage of shapes in each layer, the number of crystals per volume unit, the effective surface and area of cohesion of crystals, the layer-by-layer snow density, and the average weight of a single crystal. The crystal-morphological method yielded mass quantitative data on the processes and results of snow metamorphism under field conditions, without using complex facilities.

Formalized description of snow cover as an integral community of affine individuals (crystal shapes) was prepared using the variation and dispersion analyses, the elements of the descriptive fuzzy set theory and the information theory. The new crystals growing in snow pack acquire certain interrelationships: genetic, spatial, regular, etc., i.e., the snow cover during metamorphism acquires certain organization (situational orderliness), which we consider as a synonym of the concept of "the degree of sublimation metamorphism of snow". This degree was estimated by the value of proposed snow cover re-crystallization coefficient ( $R C$, see below).

\section{Results of Empirical Modeling for Evolutionary Processes}

\subsection{Symmetry of Crystals and Its Conformity to Hydrothermal Fields in the Snow Pack}

The morphology of a crystal surface, emerging as the direct product of the interactions in the systems crystal-vapor and crystal-crystal, is capable of providing the diverse information about the surrounding medium that is practically impossible to derive even in a laboratory, to say nothing about the conditions of work in the field. The crystal-morphological analysis of snow structure may be employed as an effective method of interpreting the conditions and processes of internal transformations in the snow cover.

The surface faceting of growing depth hoar crystals is compromising in character because the medium "attaches" to their form a symmetry not natural to the internal structure of ice. There emerges an entire series of false (distorted, induced) forms of crystal growth, the symmetry of which is a subgroup of the true crystal symmetry of ice, that is, the plane-axial prism of symmetry of the hexagonal group, with the symmetry formula $L_{6} 6 L_{2} 6 \mathrm{PaPeC}-6 / \mathrm{mmm}$ (see Foot-note to Table 1 and Figure 2a \& 2b). Such a crystal may grow under conditions of a maximally uniform medium with the symmetry of a sphere and stationary cylinder (Table 1; Figure 1a).

The hydrothermal field of the snow pack and the field of relaxation of its mechanical stresses have a lower symmetry (Figure $2 \mathrm{~d} \& 2 \mathrm{e}$ ). These fields have the property of polarity ("sign"): usually they lack a horizontal plane of symmetry, and the number of vertical planes is sharply reduced. With the same parameters of macrosymmetry of fields in the snowpack, the external symmetry of growing crystals is highly dependent on their orientation and location relative to each other. The less the elements of symmetry of the crystal and medium coincide, the lower the geometric symmetry of the resulting form. According to the statistical law of Fedorov-Grot (Grigoryev \& Zhabin, 1975; Shubnikov, 1975), the more complex the composition of the medium, the lower the symmetry of the crystal form.

The forms of the trigonal subgroup point to the polarity of the hydrothermal field in the snow on the horizontal. The pyramidal outlines of the hexagonal and ditrigonal prisms are evidence that there is polarity of the medium on the vertical. This points to frequent but rhythmically recurring changes in the temperature and in the parameters of vapor diffusion around the crystals. The trigonal-rhombohedral and trigonal-pyramidal forms characteristic of the initial stages in the development of depth hoar (Figure 1c \& 1d; and see below Figure 5b, 5e $\& 5 \mathrm{~h}$ ) grow in mediums with the symmetries of rotating cylinders and cones (see Table 1and Figure $3 \mathrm{~b} \& 3 \mathrm{~d}$ ).

The crystals of all remaining subgroups belong to the false forms of the hexagonal branch. The pseudorhombic forms point to the existence in the horizontal plane of one or two mutually perpendicular directions along which the gradients in the medium undergo marked changes. The medium is described by the symmetry $\infty=/ \mathrm{mm}$ for the prism and $\infty m$ for the pyramid. The pseudorhombic forms usually dominate amid forms of depth hoar.

When gradients of force fields change even more abruptly and frequently, development takes place of pseudomonclinic and pseudotriclinic forms - typical representatives of "mature" depth hoar (see Figure 1g \& $1 \mathrm{~h}$; and below Figure $5 \mathrm{f}, 5 \mathrm{~g}, 5 \mathrm{j} \& 5 \mathrm{k}$ ). A characteristic of prisms $2 / m$ is a medium with a "brick" symmetry - a three-axial stationary ellipsoid (see Table 1; Figure 1g and $3 b$ ). Beveled pseudomonoclinic single crystals just as all forms of the triclinic subgroup, have the lowest geometric symmetry in view of the almost non-matching of elements of symmetry of the crystal and the medium. This is due to both the non-steady state of the hydrothermal field and the contact interaction of the crystals themselves.

The growth conditions of planar and beveled pseudomonoclinic forms may be described in first approximation as the symmetry of a rotating cylinder superimposed on the flow of macroscopic diffusion in such a way. 
Table 1. Guiding morphological features of depth hoar crystals for determining their symmetry

\begin{tabular}{|c|c|c|c|}
\hline $\begin{array}{l}\text { Subgroup of } \\
\text { symmetry }\end{array}$ & $\begin{array}{l}\text { Form and formula } \\
\text { of symmetry }\end{array}$ & Shape of crystal & Symmetry of crystal-forming medium \\
\hline \multicolumn{4}{|c|}{ A. Shapes of matched orientation of growing crystals and feeding mediums } \\
\hline \multirow{5}{*}{ Hexagonal } & $\begin{array}{l}\text { Plane-axial } \\
\mathrm{L}_{6} 6 \mathrm{~L}_{2} 6 \mathrm{PaPeC}- \\
6 / \mathrm{mmm}\end{array}$ & Hexagonal prism & $\begin{array}{l}\text { Sphere } \infty L_{\infty} \infty \mathrm{PaC}-\infty / \infty \mathrm{m} \text { or stationary } \\
\text { cylinder } L_{\infty} \infty L_{2} \infty \mathrm{PaPeC}-\infty / \mathrm{mm}\end{array}$ \\
\hline & $\begin{array}{l}\text { Center } L_{6} \mathrm{PeC}- \\
6 / m\end{array}$ & $\begin{array}{l}\text { Prism with pyramidal } \\
\text { complexities }\end{array}$ & Rotating cylinder $L_{\infty} \mathrm{PeC}-\infty / m$ \\
\hline & $\begin{array}{l}\text { Plane } L_{6} 6 P a- \\
6 m m\end{array}$ & Hexagonal pyramid & Stationary cone $L_{\infty} \infty P a-\infty m$ \\
\hline & Axial $L_{6} 6 L_{2}-622$ & Hexagonal trapezohedron & Twisted cylinder $L_{\infty} \infty \mathrm{Pa}-\infty m$ \\
\hline & Primitive $L_{6}-6$ & Trigonal bipyramid & Rotating cone $L_{\infty}-\infty$ \\
\hline \multirow{5}{*}{ Trigonal } & $\begin{array}{l}\text { Plane-axial } \\
L_{3} 3 L_{2} 3 \mathrm{PaPeC}- \\
3 \mathrm{~m}\end{array}$ & Ditrigonal prism & $\begin{array}{l}\text { Stationary cylinder } L_{\infty} \infty L_{2} \infty \mathrm{PaPeC}- \\
\infty / m m\end{array}$ \\
\hline & Center $L_{3} C-3$ & Trigonal rhombohedron & Rotating cylinder $L_{\infty} \mathrm{PeC}-\infty / m$ \\
\hline & Plane $L_{3} 3 P a-3 m$ & Ditrigonal pyramid & Stationary cone $L_{\infty} \infty P a-\infty m$ \\
\hline & Axial $L_{3} 3 L_{2}-32$ & Trigonal trapezohedron & Twisted cylinder $L_{\infty} \infty L_{2}-\infty 2$ \\
\hline & Primitive $L_{3}-3$ & Trigonal pyramid & Rotating cone $L_{\infty}-\infty$ \\
\hline \multirow[t]{2}{*}{ Rhombic } & $\begin{array}{l}\text { Plane-axial } \\
3 \mathrm{~L}_{2} 2 \mathrm{PaPeC}- \\
\mathrm{mmm}\end{array}$ & $\begin{array}{l}\text { Pseudorhombic prism }+ \\
\text { pinacoid }\end{array}$ & $\begin{array}{l}\text { Stationary ellipsoid of rotation } \\
L_{\infty} \infty L_{2} \infty \mathrm{PaPeC}-\infty / \mathrm{mm}\end{array}$ \\
\hline & $\begin{array}{l}\text { Plane } L_{2} 2 \mathrm{~Pa}- \\
\mathrm{mm} 2\end{array}$ & $\begin{array}{l}\text { Pseudorhombic pyramid, } \\
\text { prism }\end{array}$ & $\begin{array}{l}\text { Elliptically stationary cone of rotation } \\
L_{\infty} \infty L_{2} \infty P a-\infty m\end{array}$ \\
\hline \multirow{3}{*}{ Monoclinic } & $\begin{array}{l}\text { Plane-axial } L_{2} \mathrm{PeC} \\
-2 / m\end{array}$ & $\begin{array}{l}\text { Rhombic prism }+ \text { pinacoid } \\
\text { or three pinacoids }\end{array}$ & $\begin{array}{l}\text { Three-axial stationary ellipsoid } 3 \mathrm{~L}_{2} 3 \mathrm{PaC} \\
-\mathrm{mmm}\end{array}$ \\
\hline & Axial $L_{2}-2$ & Pseudorhombic pyramid & Three-axial fixed cone $L_{2} 2 \mathrm{~Pa}-m m 2$ \\
\hline & Plane $P e-m$ & $\begin{array}{l}\text { Pseudorhombic prism with } \\
\text { orthogonal axes }\end{array}$ & $\begin{array}{l}\text { Three-axial horizontally rotating ellipsoid } \\
3 L_{2} \mathrm{PaC}-m\end{array}$ \\
\hline \multicolumn{4}{|c|}{ B. Shapes of unmatched orientation of growing crystals and mediums } \\
\hline Monoclinic & Plane $P a-m$ & $\begin{array}{l}\text { Regular oblique } \\
\text { pseudomonoclinic prism } \\
\text { or pyramid }\end{array}$ & $\begin{array}{l}\text { Rotating cylinder or three-axial ellipsoid } \\
\text { superimposed on a stationary cylinder or } \\
\text { cone }\end{array}$ \\
\hline \multirow{2}{*}{ Triclinic } & Center $C_{i}\left(L_{i}\right)-\overline{1}$ & $\begin{array}{l}\text { Irregular oblique } \\
\text { pseudotriclinic prism }\end{array}$ & \multirow{2}{*}{$\begin{array}{l}\text { Rotating cylinder and two three-axial } \\
\text { stationary ellipsoids on different planes } \\
\text { imposed on a stationary cylinder or cone }\end{array}$} \\
\hline & Primitive -1 & $\begin{array}{l}\text { Irregular oblique } \\
\text { pseudotriclinic pyramid }\end{array}$ & \\
\hline
\end{tabular}

Note: There are adduced the formulas of symmetry by Brave and symbols of symmetry by International nomenclature of German-Mogen (Shubnikov, 1975). In formula of symmetry: $L_{n}-$ the axis of symmetry of the $n$-th order; $P_{a}$ - the plane of symmetry parallel to the main crystallographic (optic) axis of crystal; $P_{e}-$ the plane of symmetry perpendicular to this axis; $C$ - the center of symmetry (inversion). In International nomenclature: the axes of symmetry are indicated by figures corresponding to the orders of the axes, and planes are indicated by the character $m$. If the plane of symmetry is perpendicular to the axis of symmetry, then a dash is placed between the two characters; if the plane passes through the axis, then the characters are written together. 

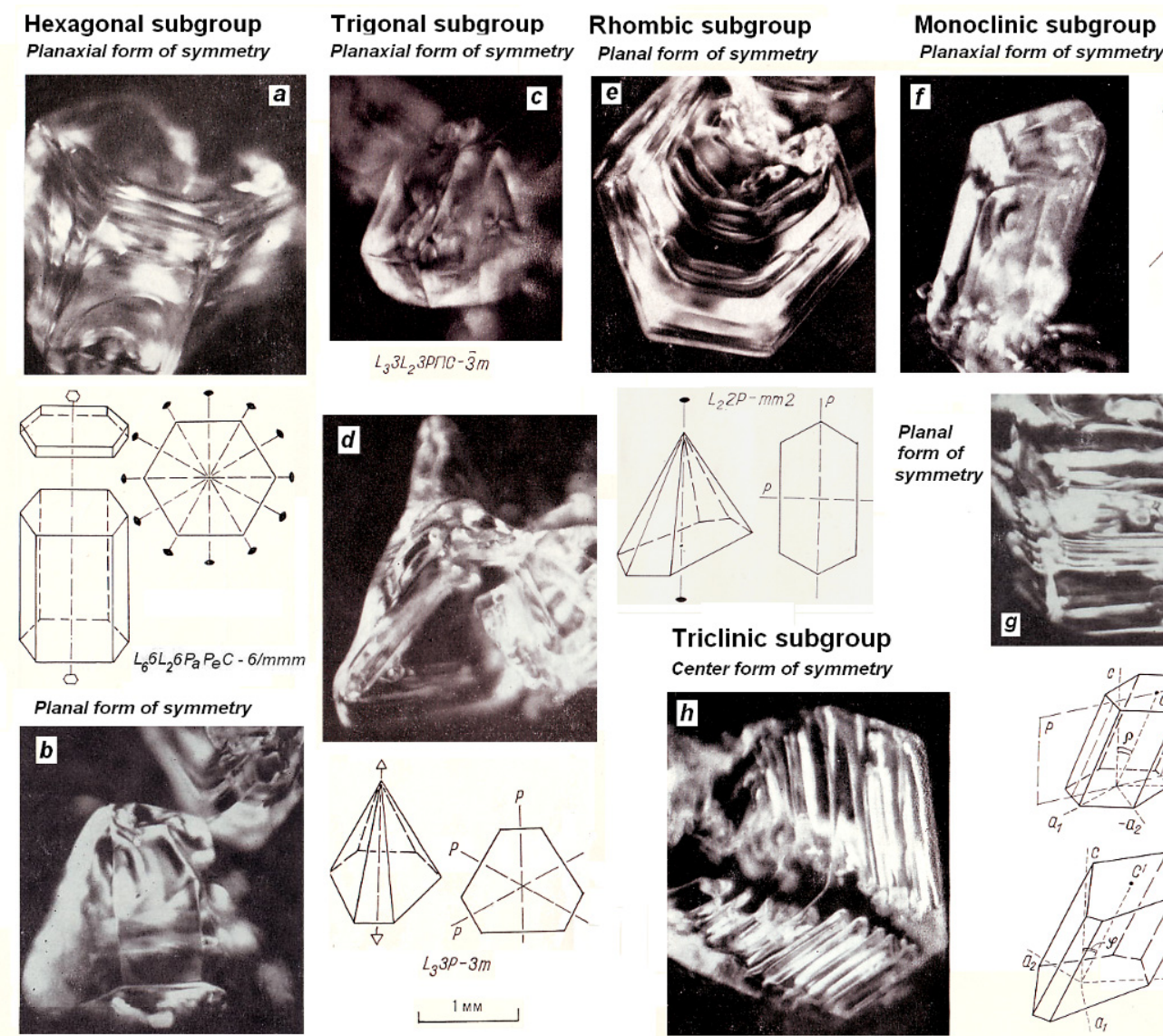

Planaxial form of symmetry
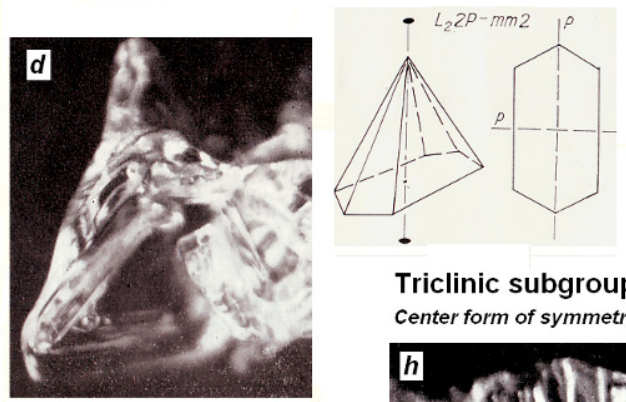

Triclinic subgroup
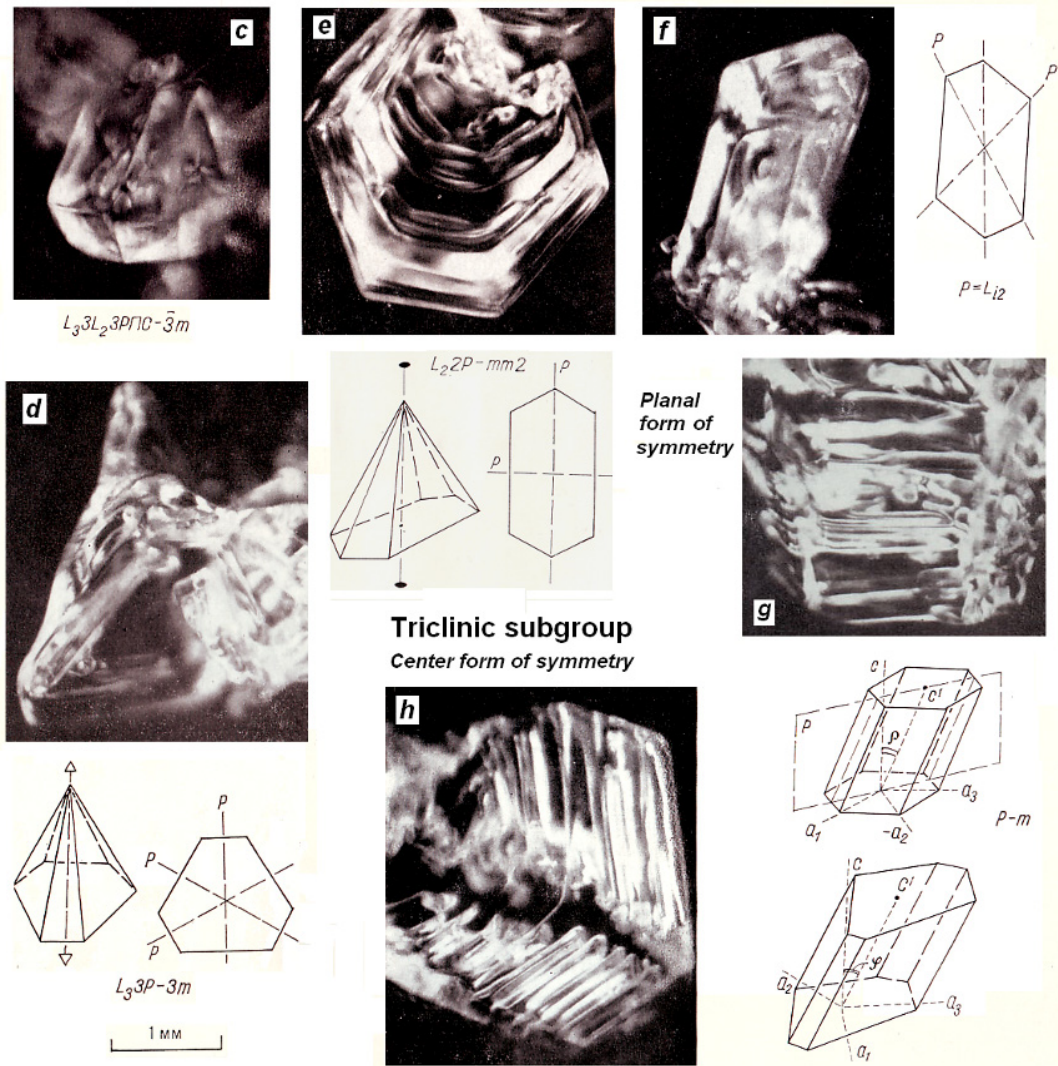

Figure 1. Geometric symmetry of the crystals of sublimation metamorphism

The vector of this flow is located on the plane of the rotating cylinder (see Figure 3c). Similar conditions may occur during sharp and frequent temperature fluctuations in. the snow layer (these fluctuations geometrically signify a change of "sign" of rotation of the cylinder). As a result, the crystal is forced to expand on the rotation axis of the cylinder, that is, in a general case horizontally.

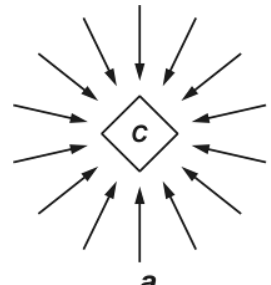

a

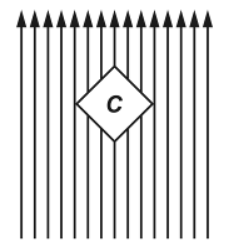

d

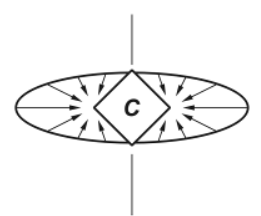

b

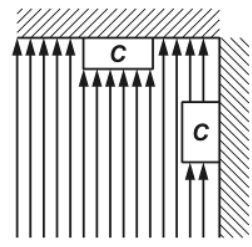

e

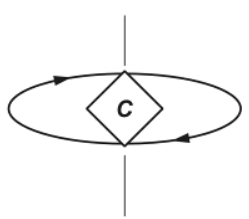

c

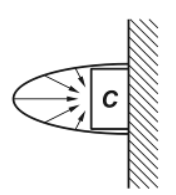

f

Figure 2. Simple types of symmetry of crystal-forming mediums in the snow cover

$\boldsymbol{a}$ - sphere symmetry; $\boldsymbol{b}, \mathrm{c}$ - symmetry of stationary and rotating cylinders, respectively; $\boldsymbol{d}$ - symmetry of a stationary cone; $\boldsymbol{e}$ - growth of crystals attached to a wall in a unidirectional medium with cone symmetry; $\boldsymbol{f}$ same in a medium with cylinder symmetry. 


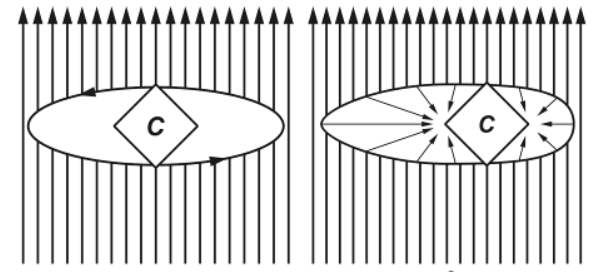

a

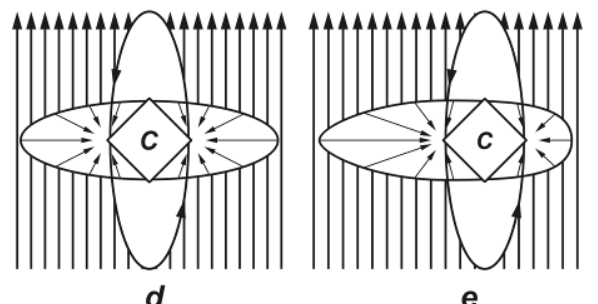

e

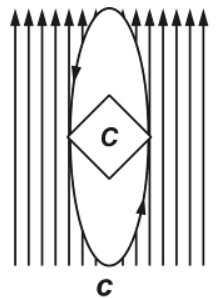

C

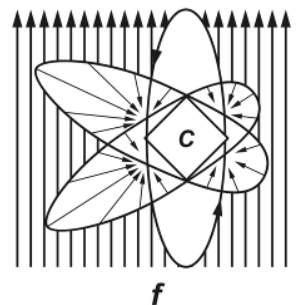

Figure 3. Composite types of symmetry of crystal-forming mediums in the snow cover

$\boldsymbol{a}, \boldsymbol{c}$ - combination of feeding fluxes with the symmetries of a cone and rotating cylinder; $\boldsymbol{b}$ - combination of fluxes with symmetries of a cone and stationary ellipsoid of rotation; $d, e, f$-various combinations of the symmetries of a feeding medium - cone, stationary and rotating cylinder and stationary ellipsoid of rotation. Other nomenclature as in Figure 2.

Similar compression of form is also caused by the re-crystallization according to the Rikke principle (Grigoryev, 1965; Grigoryev \& Zhabin, 1975) - in conditions of one-sided pressure (compression). If the field of local diffusion or local stresses in the horizontal plane is described additionally by the symmetry of a stationary cylinder (see Figure 3, $d$ ), then there develop oblique or planar, but regular in their base, hexagonal forms. When the horizontal symmetry of a three-axial stationary ellipsoid is present in the local medium (see Figure $3, e$ ) compressed and beveled pseudomonoclinic prisms and pyramids form with a single vertical plane of symmetry.

Finally, mediums with the most complex shape of symmetry (see Figure, $3, f$ ) are characteristic of pseudotriclinic forms. At least three locally rotating flows are superimposed on a unidirectional macroforce field. One of them with the symmetry of a rotating cylinder causes the form to compress. The two others move on planes located at an angle to the vector of the macroforce field, and they have the symmetry of a three-axial stationary ellipsoid. This gives the crystal form a "triclinic" outline (see Figure 1, $h$, and below Figure 5, $g, j, k$ ).

As is known, layers with well-developed depth hoar often have a well-defined vertical columnar (fibrous) texture. The fibers are composed of not only relatively symmetrical columnar crystals but also planar single crystals with reduced symmetry. The latter often develop on the walls of air pores. The higher symmetry of the crystals points to those situations when the pores are fairly evenly distributed in the three-dimensional space of the snow layer and, consequently, the areas of the contacts between particles are of one order both on the layers and in the vertical cross section. On the other hand, the well-defined dissymmetry of the forms, particularly the planar types, is an indication that there is a prevalence of vertical pores and accretions (clasters) weakly connected to each over the extent of the snow stratum. It is evident that in the second case the layer is more brittle to sublayer shear and hence more avalanche-hazardous (with the same specific area of contacts). A reduction in the symmetry of growing crystals in its mass is an indication that a dangerous columnar texture has developed in the layer.

\subsection{Deterministic Model of Sublimation Snow Metamorphism}

Our stationary observations of many years in the plain and mountain taiga of Siberia and the Far East (see below, Figure 9) have demonstrated that time (the age of snow layer) is the key factor, the coordinate of which is necessary for consideration of conformity to natural laws and results of snow metamorphism. Stage growth of crystals depends by $45-60 \%$ on the age of the layer. For example, at low-mountain Regions of the Lower By-Amur river it has been revealed the next dependence percentage portion of skeleton crystal shapes $N_{\text {sk }}$ from the age of given genetic snow layer $\tau$ :

$$
N_{\mathrm{sk}}=0.3136 \cdot \tau-545 ; \mathrm{R}=0.728 ; \mathrm{R}^{2}=0.530
$$

There $\mathrm{R}$ and $\mathrm{R}^{2}$ - accordingly the coefficients of correlation and determination. The height above the ground of 
the latter is exhibited much weaker (by $15-35 \%$ ). The local site of snow pack has the minimum effect (0.5-5.5\%) on crystal growth. Time makes snow re-crystallization processes irreversible and causes translational motion in crystal growth and in "alteration of generations" of crystal forms, in the alternation of periods of their development and degradation. The main evolutionary unit of snow cover is a genetically integral snow layer as an elementary self-developing natural community of crystalline individuals of different shape.

The author has developed an empirical deterministic model describing the unclosed evolutionary sublimation-metamorphic cycle of seasonal snow cover and regional (polymorphic) versions of this cycle (Figure 4). The superposition of natural symmetries in the snowpack acts as a specific process distended in time. The medium (the diffusion field of water vapor) imposes its symmetry on the growing crystal with some graduation, with staged changeover in the mechanisms of interaction in the systems crystal-vapor and crystal-crystal. Dry snow cover during the course of winter tends to traverse the directional trajectory of the sublimation-metamorphic cycle consisting of three periods: destructive (I), constructive (II) and regressive (III). These periods include nine stages of growth and subsequent decomposition of the crystals (Figure 5): the fragmentation stage $\left(\mathrm{I}_{1}\right)$, polyhedral $\left(\mathrm{I}_{2}\right)$, stages of planar and columnar faceted prisms $\left(\mathrm{II}_{1}\right.$ and $\left.\mathrm{II}_{2}\right)$, semiskeletal and skeletal stages $\left(\mathrm{II}_{3}\right.$ and $\left.\mathrm{II}_{4}\right)$, sectorial $\left(\mathrm{III}_{1}\right)$, plate-like $\left(\mathrm{III}_{2}\right)$ and, finally, the sublimation-firn stage $\left(\mathrm{III}_{3}\right)$. Crystals in each growth stage produce corresponding classes of forms with the same names. Each layer of the snowpack passes through similar stages of evolution, designated as phases of metamorphism (Figure6). All stage forms of constructive metamorphism belong to the category of depth hoar.

Destructive snow metamorphism (decomposition of primary crystals and their transformation into shapeless "grains") is effective only under the weak gradient thermal field of snow pack, therefore it is the longest in the regions with soft (oceanic) winters. In strongly continental winter conditions, the "grainy" (polyhedral) stage actually drops out, while the fragmentation stage becomes shorter.

The degree of snow re-crystallization is determined by the efficiency of constructive metamorphism (see Figure $3, B)$, which takes the most part of winter in continental regions. Variation and statistical analysis has shown (Kolomyts, 1976, 1977), that crystal-morphological complication of the layer is conditioned by selection of crystals during their growth. The groups of particles are converted from one crystalline form into another not simultaneously; therefore, the layer is gradually enriched in various classes of crystal forms.
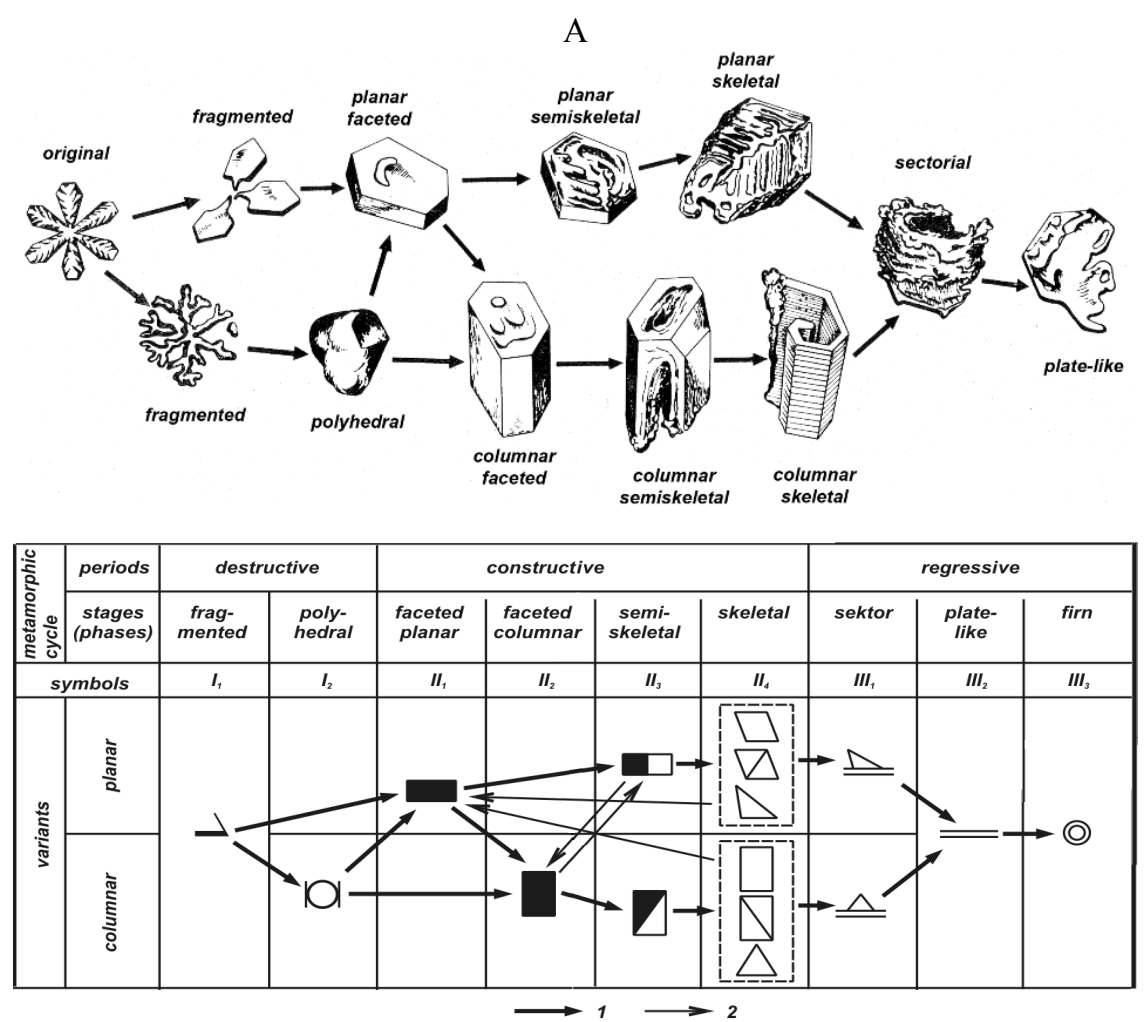

B

Figure 4. The sublimation-metamorphic cycle of dry seasonal snow 
$\boldsymbol{A}$ - the main milestones of crystal ontogenesis in dry snow cover, their individual stage growth and following decomposition. Shown are two main variants (programs) of sublimation ontogenesis are showed: planar (above) and columnar (below).

$\boldsymbol{B}$ - principle scheme of sublimation-metamorphic cycle. 1 - transitions of the basic (elemental) chain of transformations of crystal forms and snow layers; 2 - transitions of age complexity in the structure of layers and their shift from one variant (program) of metamorphism to another.

In the beginning of constructive metamorphism, crystals comprise comparatively homogenous classes of forms subject to the laws of normal (Gaussian) distribution. At the stages of faceted growth, crystals are yet of comparatively small sizes, therefore the tendency to simplicity and perfection of the form is predominant, according to the Gibbs-Curie-Wulff principle (Honigman, 1958; Shafranovsky, 1968; Grigoryev \&habin, 1975). Solid crystal forms of faceted classes are for the most part highly symmetrical (hexagonal, trigonal and rhombic), with repeatedly growing smooth facets (see Figure $5, a, b, c$; and also Figure $1, b, c$ ). They are a morphological manifestation of the initial correct growth of crystals.

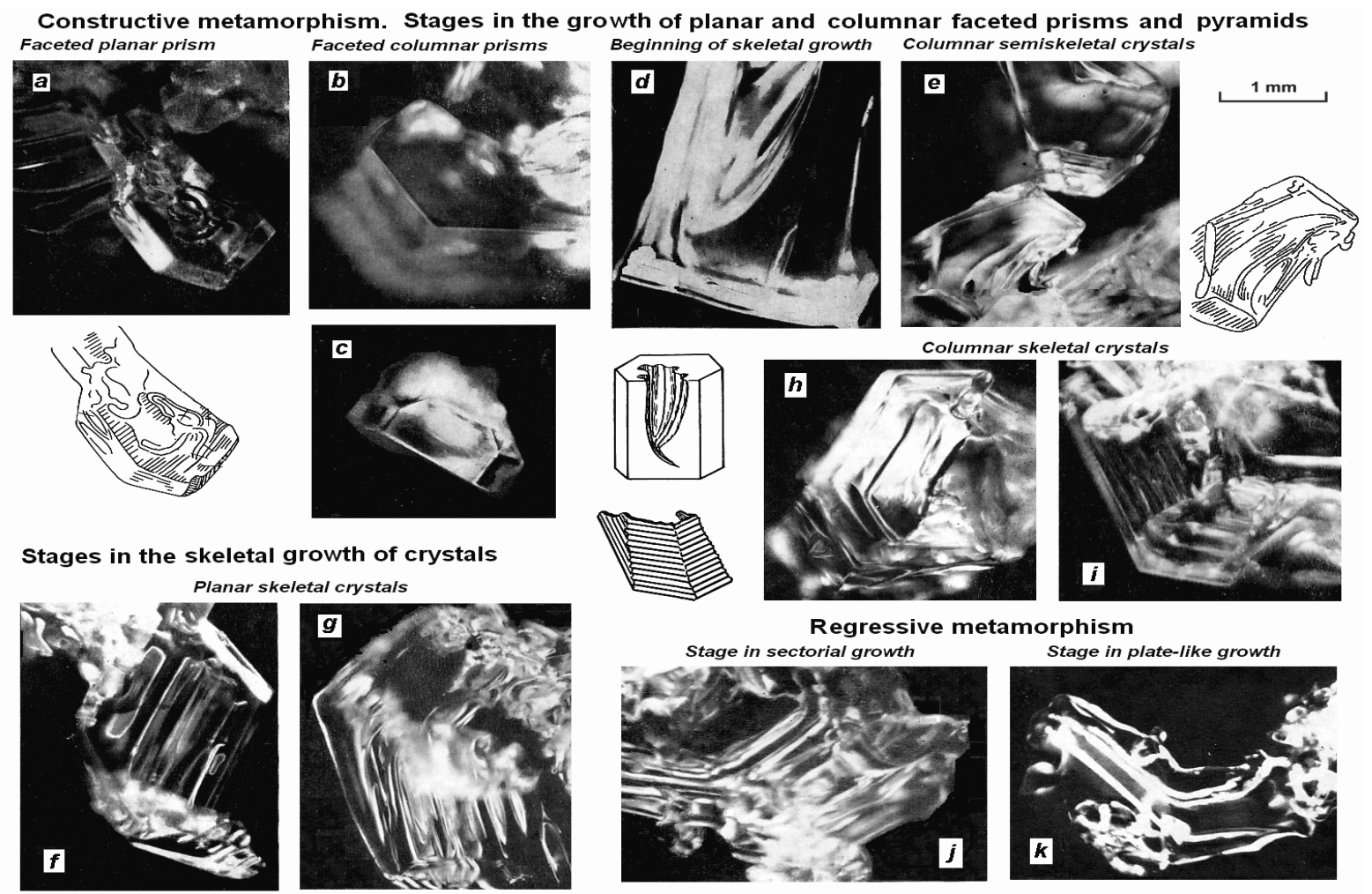

Figure 5. Stage shapes of the growth and decomposition of depth hoar crystals in loose snow

Faceted growth is accompanied by plastic-viscous deformations of snow ice crystal lattice resulting in its slow setting and packing. The duration of faceted stages and phases abruptly increases and the rate of crystal growth decreases in the direction from lower to upper snow layers. 

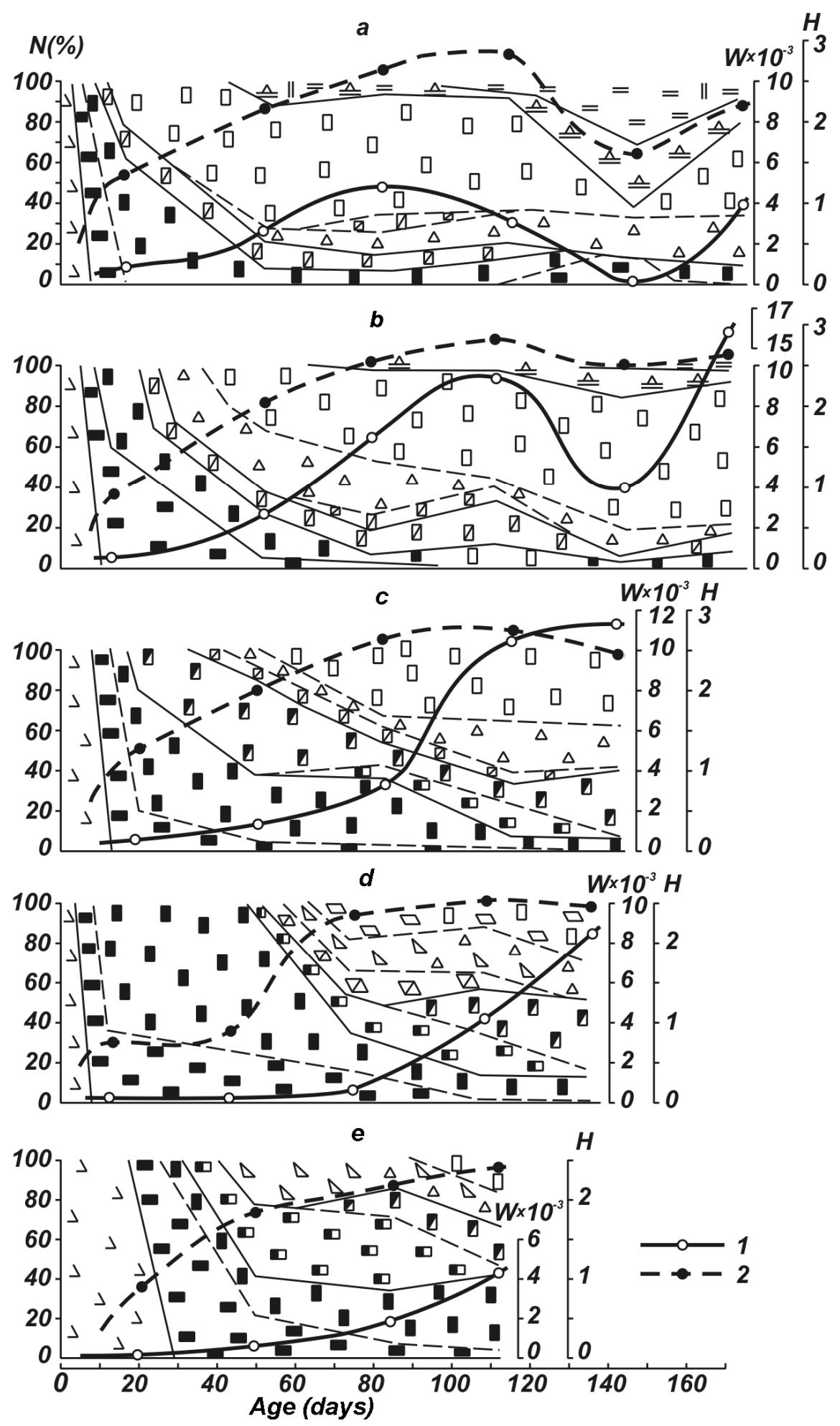

Figure 6 . The age changes of structure parameters of snowpack layers in taiga-swamped nature complex (middle taiga of West-Siberian Plain, winter of years 1968/69)

Parameters: $N$ - portions of different classes and types of crystal forms (by there summary cubic capacity); 1 average cubic capacity of crystal $\left(W \cdot 10^{-3}, \mathrm{~cm}^{3}\right) ; 2-$ the information measure of structural diversity (negentropy) of layers $(H$, bytes). Height of the snow layer over soil surface, $\mathrm{cm}: a-0 ; b-10 ; c-30 ; d-40 ; e-60$. The symbols of crystal forms see on Figure 4, $B$, and in Table 4.

Later on when the crystals reached the certain critical sizes they are transformed first into semi-skeletal forms, 
with appearance of "multi-sloped caps" and development of caverns (see Figure 5, $d, e$ ). After that these forms turn into own skeletal crystals - openwork, hollow, with large striated facets (see Figure $1, d$, e, and Figure $5, h$, i). Such morphological complication implies gradual inclusion of the medium into a crystal (in accordance with the principle of superposition of symmetries) and development of adaptation mechanisms providing its further growth (Sheftal, Kolomyts, 1973). This is the first qualitative leap in the metamorphic cycle. The adaptive tendency of particle growth (by the principle of maximum rate of crystallization completion) becomes predominant, giving great diversity of skeletal forms. The rate of metamorphism drastically increases, however there is an abrupt decrease in the real symmetry of "forced" forms, up to the monoclinic plane and triclinic primitive symmetry (see Figure $1, g, h$, and Figure $5, f, g$ ).

Regressive metamorphism is the backward "ovement"of crystalline individuals and snow layers: in the direction of simplification of their structure and approach to the state with the minimum of shape diversity (negentropy, see Figure 6). This is the second qualitative leap in the metamorphic cycle. It manifests itself in the splitting and breakup of crystals under relatively unchanged external conditions (Sheftal, Kolomyts, 1973), hence it may be called snow "geing" in the true sense of this notion (Kolomyts, 1984). During the sectorial and plate-like stages of this period (see Figure $5, j, k$ ), the sizes of particles abruptly decrease and many skeletal and faceted forms disappear.

The growth of crystals in the semi-skeletal, skeletal and sectorial stages can proceed in accordance with two variants, or program (see Figure 4): columnar $\left(\mathrm{II}_{3}{ }^{\mathrm{col}} \rightarrow \mathrm{II}_{4}{ }^{\mathrm{col}} \rightarrow \mathrm{W}_{1}{ }^{\mathrm{col}}\right.$ ) and planar $\left(\mathrm{II}_{3}{ }^{\mathrm{pl}} \rightarrow \mathrm{II}_{4}{ }^{\mathrm{pl}} \rightarrow \mathrm{W}_{1}{ }^{\mathrm{pl}}\right)$. These variants provide two types of crystal forms in each of the mentioned classes. Any of the variants of growth can dominate in the snow layer or in combination with the other provide a mixed variant. Variants (or branches) of the sublimation-metamorphic cycle (columnar, planar, mixed) are predetermined on the one hand by the temperature state of the snow and, on the other, by the action of the force of gravity whose structural effect is dependent on the depth of deposition of the given layer, density of the overlying layers and the time of the loading action, that is, the age of the layer. Accordingly, in the first case the variants are branches of the sublimation thermal metamorphism of snow. The pressure factor displays only in the middle and lower layers of deep and dense depositions and causes of sublimation dynamic metamorphism. Columnar variant are predetermined under relatively high temperatures and faint temperature gradients (soft winter conditions), planar ones - under low temperatures and there sharp and frequent fluctuations (conditions of high continental winters). The field of snow compression is also of certain significance.

The evolutionary model of snow cover by no means envisages the passing by the sets "crystal form", "snow layer" and "snowpack" necessarily through all periods and stages (phases) of snow re-crystallization under any winter conditions. The point at issue is the invariant process of sublimation metamorphism as the major tendency of evolution of dry snow cover.

\subsection{Evolutionary Character of the Sublimation-mtamorphic Cycle}

The sublimation-metamorphic cycle in its principal features is invariant and characterizes the process of snow cover self-development, which can be expressed by the known in ecology logistic (sigmoidal) curve (Odum, 1983). The trajectories of parameters $W$ and $H$ have similar logistic-sigmoidal character (see Figure 6). Irrespective of the macro- and meso-sites (zonal-regional and vertical differentiation of landscapes), local (topological) geomorphological and hydro-edaphic factors, continentality of a given winter (within a certain range), snow density and height of the layer above the ground, each genetic group of crystals passes fully or partially through fundamentally the same stages of morphological changes, successively superseding each other. This process displays with bigger or lesser velocity under any temperatures, temperature gradients and intensity of vapor macroscopic diffusion (Table 2). Passing through these stages is conditioned exclusively by internal interactions between growing crystals and dissymmetric hydrothermal fields in snow pack.

Solid crystal forms of faceted classes are for the most part highly symmetrical (hexagonal, trigonal and rhombic), with repeatedly growing smooth facets. They are a morphological manifestation of the initial correct growth of crystals, when particles have not yet reached the critical sizes (Honigman, 1958; Grigoryev, 1965). Then they are transformed first into semi-skeletal shapes (with development of caverns) and further into skeletal crystals (openwork, hollow, with large striated facets). Such morphological complication implies gradual inclusion of the medium into a crystal (in accordance with the Curie principle of superposition of symmetries) and development of adaptation mechanisms providing its further growth (Sheftal, 1973; Sheftal \& Kolomyts, 1973). Accordingly, there is an abrupt decrease in the real symmetry of these "forced" shapes, up to the monoclinic plane and triclinic primitive symmetry.

Invariance of the metamorphic cycle is expressed in stage change of the classes of crystalline shapes. The types 
of forms within each class characterize different variants of this cycle, which are determined by the external regulatory influence: the hydrothermal regime of the whole soil-snow-air system. External environment plays the role of an indicating mechanism switching over the metamorphic cycle trajectory to some or other development program. The major external factor is the degree of winter continentality, which determines the general level of snowpack cooling and nonstationarity of thermal field in its separate layers. The regime of snow accumulation determining the field of snow compression is also of certain significance.

The evolutionary model of snow cover by no means envisages the passing by the sets "crystal form", "snow layer" and "snowpack" necessarily through all periods and stages (phases) of snow re-crystallization under any winter conditions. The point at issue is the invariant process of sublimation metamorphism as the major tendency of evolution of dry snow cover.

Table 2. Main hydrothermal parameters of snow during successive winter periods of years 1968/69 and by different phase states of snow layers being on various height above soil (middle taiga of West Siberian Plain)

$A$. Primary cedar/silver/-fir/spruce small-grass/green moss forest on the upland watershed area

\begin{tabular}{|c|c|c|c|c|c|c|c|c|c|c|c|c|}
\hline \multirow{2}{*}{ Winter period } & \multicolumn{4}{|c|}{$\mathrm{h}=0 \mathrm{~cm}$} & \multicolumn{4}{|c|}{$\mathrm{h}=20 \mathrm{~cm}$} & \multicolumn{4}{|c|}{$\mathrm{h}=40 \mathrm{~cm}$} \\
\hline & $t$ & $d t / d h$ & $i$ & $P H$ & $t$ & $d t / d h$ & $i$ & $P H$ & $t$ & $d t / d h$ & $i$ & $P H$ \\
\hline 3.XI-7.XII & -5.4 & -0.3 & 2.2 & $\mathrm{II}_{2}^{\mathrm{c}}-\mathrm{II}_{3}{ }^{\mathrm{c}}$ & -12.1 & -0.3 & 1.4 & $\mathrm{I}_{1}-\mathrm{II}_{2}^{\mathrm{c}}$ & - & - & - & - \\
\hline 7.XII-3.I & -5.1 & -0.3 & 2.0 & $\mathrm{II}_{4}^{\mathrm{c}}$ & -11.3 & -0.3 & 1.4 & $\mathrm{II}_{2}{ }^{\mathrm{c}}-\mathrm{II}_{3}{ }^{\mathrm{c}}$ & -7.8 & -0.4 & 1.1 & $\mathrm{I}_{1}-\mathrm{I}_{2}$ \\
\hline $3 . \mathrm{I}-8 . \mathrm{II}$ & -7.3 & -0.4 & 2.1 & $\mathrm{II}_{4}{ }^{\mathrm{c}}$ & -14.0 & -0.3 & 1.3 & $\mathrm{II}_{3}{ }^{\mathrm{c}}-\mathrm{II}_{4}{ }^{\mathrm{c}}$ & -22.5 & -0.4 & 0.5 & $\mathrm{II}_{1}{ }^{\mathrm{p}}-\mathrm{II}_{3}{ }^{\mathrm{p}}$ \\
\hline 8.II - 13.III & -5.8 & -0.2 & 1.1 & $\mathrm{II}_{4}{ }^{\mathrm{c}}$ & -9.9 & -0.2 & 0.9 & $\mathrm{II}_{4}^{\mathrm{c}}$ & -13.1 & -0.2 & 0.6 & $\mathrm{II}_{3}^{\mathrm{p}}$ \\
\hline 13.III - 8.IV & -3.1 & -0.1 & 0.8 & $\mathrm{III}_{1}^{\mathrm{c}}$ & -5.2 & -0.1 & 0.7 & $\mathrm{II}_{4}{ }^{\mathrm{c}}$ & -7.0 & -0.1 & 0.2 & $\mathrm{II}_{3}{ }^{\mathrm{p}}-\mathrm{II}_{4}{ }^{\mathrm{p}}$ \\
\hline
\end{tabular}

B. Cedar/pine small-shrub/sphagnum light forest on the interfluve drop

\begin{tabular}{|c|c|c|c|c|c|c|c|c|c|c|c|c|}
\hline \multirow{2}{*}{ Winter period } & \multicolumn{4}{|c|}{$\mathrm{h}=0 \mathrm{~cm}$} & \multicolumn{4}{|c|}{$\mathrm{h}=20 \mathrm{~cm}$} & \multicolumn{4}{|c|}{$\mathrm{h}=40 \mathrm{~cm}$} \\
\hline & $t$ & $d t / d h$ & $i$ & $P H$ & $t$ & $d t / d h$ & $i$ & $P H$ & $t$ & $d t / d h$ & $i$ & $P H$ \\
\hline $3 . \mathrm{XI}-8 . \mathrm{XII}$ & -4.3 & -0.5 & 3.6 & $\mathrm{II}_{3}{ }^{\mathrm{c}}-\mathrm{II}_{4}{ }^{\mathrm{c}}$ & -16.6 & -0.4 & 1.4 & $\mathrm{I}_{1}-\mathrm{II}_{1}$ & - & - & - & - \\
\hline 8.XII - 5.I & -3.6 & -0.3 & 3.8 & $\mathrm{II}_{4}^{\mathrm{c}}$ & -9.9 & -0.2 & 1.4 & $\mathrm{II}_{1}-\mathrm{II}_{2}{ }^{\mathrm{c}}$ & - & - & - & - \\
\hline $5 . \mathrm{I}-10 . \mathrm{II}$ & -4.9 & -0.4 & 3.7 & $\mathrm{II}_{4}{ }^{\mathrm{c}}-\mathrm{III}_{1}$ & -11.5 & -0.2 & 1.3 & $\mathrm{II}_{2}{ }^{\mathrm{c}}-\mathrm{II}_{3}{ }^{\mathrm{c}}$ & -18.8 & -0.5 & 0.6 & $\mathrm{I}_{1}-\mathrm{II}_{1}$ \\
\hline 10.II - 15.III & -3.3 & -0.1 & 2.3 & $\mathrm{III}^{1 \mathrm{c}}$ & -7.5 & -0.1 & 0.9 & $\mathrm{II}_{4}^{\mathrm{c}}$ & -11.8 & -0.2 & 0.7 & $\mathrm{II}_{2}^{\mathrm{p}}$ \\
\hline 15.III - 19.IV & -1.8 & -0.1 & 1.4 & $\mathrm{III}_{1}{ }^{\mathrm{c}}-\mathrm{III}_{2}$ & -3.7 & -0.1 & 0.7 & $\mathrm{II}_{4}{ }^{\mathrm{c}}$ & -5.7 & -0.1 & 0.5 & $\mathrm{II}_{3}{ }^{\mathrm{p}}$ \\
\hline
\end{tabular}

Note: $t$ - everage temperatura, $\mathrm{C}^{0} ; d t / d h$ - temperature gradient, degree $/ \mathrm{cm}$;

$i \cdot 10^{-3}$ - index of vapor diffusion, $\mathrm{gr} / \mathrm{cm}^{2} \cdot$ day; $P H$ - phase state of snow layer (see on Figure $4, B$ ).

\section{Crystal-morphological Classification for Snow on the Ground}

\subsection{The Valuation of Existing Classifications}

None of the sciences has done without systematization of objects under study. Systematization is division of an entire set of objects into parts by the signs of similarity and their ranking by any sign so that the lowest rank would be referred to the highest one as a part to the whole. The first and second parts of systematization are called classification and taxonomy, respectively (Armand, 1975). In the International glaciological literature, systematization of snow structure is usually referred to as "Classification for the snow of the ground". This term seems to be not quite correct. In our point of view, it would be more proper to term such classifications as "Guidance for description of seasonal snow cover".

Rather detailed chronology of development of foreign guidance on snow studies, from the middle of the $19^{\text {th }}$ century to 2000, is presented in the work (Pielmeier \& Schneebeli, 2003), which shows gradual transition from the merely descriptive method of structural analysis of snow sections to the texture-morphological method, with saturation of qualitative descriptions with metric and micromorphological characteristics, as well as the signs of the respective mechanical properties of snow. The advantage and practical value of such guides (Schaefer, Klein, \& de Quervain, 1954; Sommerfeld \& La Chapelle, 1970; Colbeck, Akitaya, \& Armstrong, 1990; Fierz et al., 
2009) are that they reflect, as far as possible, all natural processes of snow cover formation and further changes: periodicity of snow accumulation, wind-blown snow stream and compaction of snow, part-melting and moistening of snow during thaws, with formation of ice and firn crusts, settling of snow, sublimation, regelation and re-crystallization processes of metamorphism in different layers of snow pack and, finally, the processes of firnification of snow resulting in its transformation into ice. During the field study of snow sections, these classifications may show the prevalent type of transformation of the structure and texture of different snow layers in the preceding period: sublimation, regelation, re-crystallization, etc. It means restoration of external conditions for internal transformation of snow cover.

\subsection{Construction of the Classification}

Crystal-morphological classification of snow worked out by the author may be attributed to Supplement A ("Grain shape classification") of last "International Classification for Seasonal Snow" (Fierz et al., 2009). Our classification have been created on the basis of conformity to natural laws of the ontogeny of crystals in a snow pack is constructed on the genetic principle: all categories of the forms of individual crystals correspond to certain periods and stages of the sublimation-metamorphic snow cycle. The following 17 major specific crystalline forms revealed in dry snow cover were taken for taxonomic analysis: 1, 2, skeleton apical planar and spatial (dendrites); 3, isometric polyhedral; 4, 5, faceted prismatic planar and columnar; 6, faceted pyramidal-prismatic ("bullets"); 7, 8, semiskeleton planar and columnar; skeleton rib-like prismatic and pyramidal forms: 9, 10, planar; 11-13, columnar; 14, skeleton rib-like pyramidal-prismatic ("cups" and "wineglasses"); 15, 16, sectorial planar and columnar; 17, plate-like skeleton rib-like.

These groups of forms were arranged on the basis of discrete signs, i.e., by the presence or absence of each from $22^{\text {th }}$ morphological properties of crystal (Kolomyts, 1976, 1977): the dominant growth by axis $c$ or $a$, the major type of facets, the presence or absence of crystal polarity, open cavities, the step structure of facets, sectorial excrescences, etc.

The well-known method of numerical taxonomy was used for systematization, making it possible to represent the crystal shape in quantitative form. Numerical taxonomy was based on the dichotomous principle with association or similarity coefficients $S$ calculated by the formula (Bailey, 1967):

$$
S=\left(n_{11}+n_{00}\right) / N
$$

where $N$ - the total number of signs, $\mathrm{n}_{11}$ and $\mathrm{n}_{00}$ - the number of signs present and absent in both taxons, respectively. The matrix of coefficients of similarity of the taxonomic units has been constructed on the basis of calculations (Table 3). It clearly shows 5 groups of taxons: integral wholes within which individual crystals have $\mathrm{S} \geq 0.7$ (no less than $70 \%$ significance level of similarity). These groups have been designated as the classes of crystalline shapes (see above), which are similar in the dominant faceting elements (facets, edges, tips) and in the degree of external manifestation of the inner symmetry of individual crystals. The classes of crystal forms have the following names: (1) fragmentation stage, (2) polyhedral, (3) faceted, (4) semi-skeleton, and (5) a complex of skeleton classes. The classes are grouped into three genetic types of deposited dry snow. The first and second classes are referred to the types of primary idiomorphic and isomorphic snow, respectively; other classes are referred to the type of secondary idiomorphic snow.

The complex of skeleton crystals is characterized by the greatest diversity of shapes and degrees of similarity between them $(S=0.64-0.91)$. It can be divided into five groups with significance level of characteristics exceeds $75 \%$. The first and second groups form the properly skeleton class as the highest stage of crystalline forms. Compositional and degrading skeleton forms are referred to the sectorial class (third group), while the forms that have completely lost visible skeleton contours but preserved skeleton rib-like growth type are referred to the planar class.

Based on the thermal conditions of snow pack re-crystallization, it is possible to single out the second major taxonomic category: the type of crystalline shapes. The guideline attribute for differentiation of the types is the direction of prevailing crystal growth (by axis $c$ or $a$ ). It is accompanied by a number of concomitant morphological characters: the presence or absence of caverns and cavities, the degree of crystal polarity, predomi nance of basal pinacoidal, prismatic, or pyramidal facets, their commensurability, etc. There are two main types of the forms: planar and columnar. They are "through" taxons since they are traced in nearly all classes of the forms. Compared to the classes, the types of forms have altogether lower values of $S(0.68-0.73)$. 
Table 3. Matrix of likeness coefficients of taxonomic units

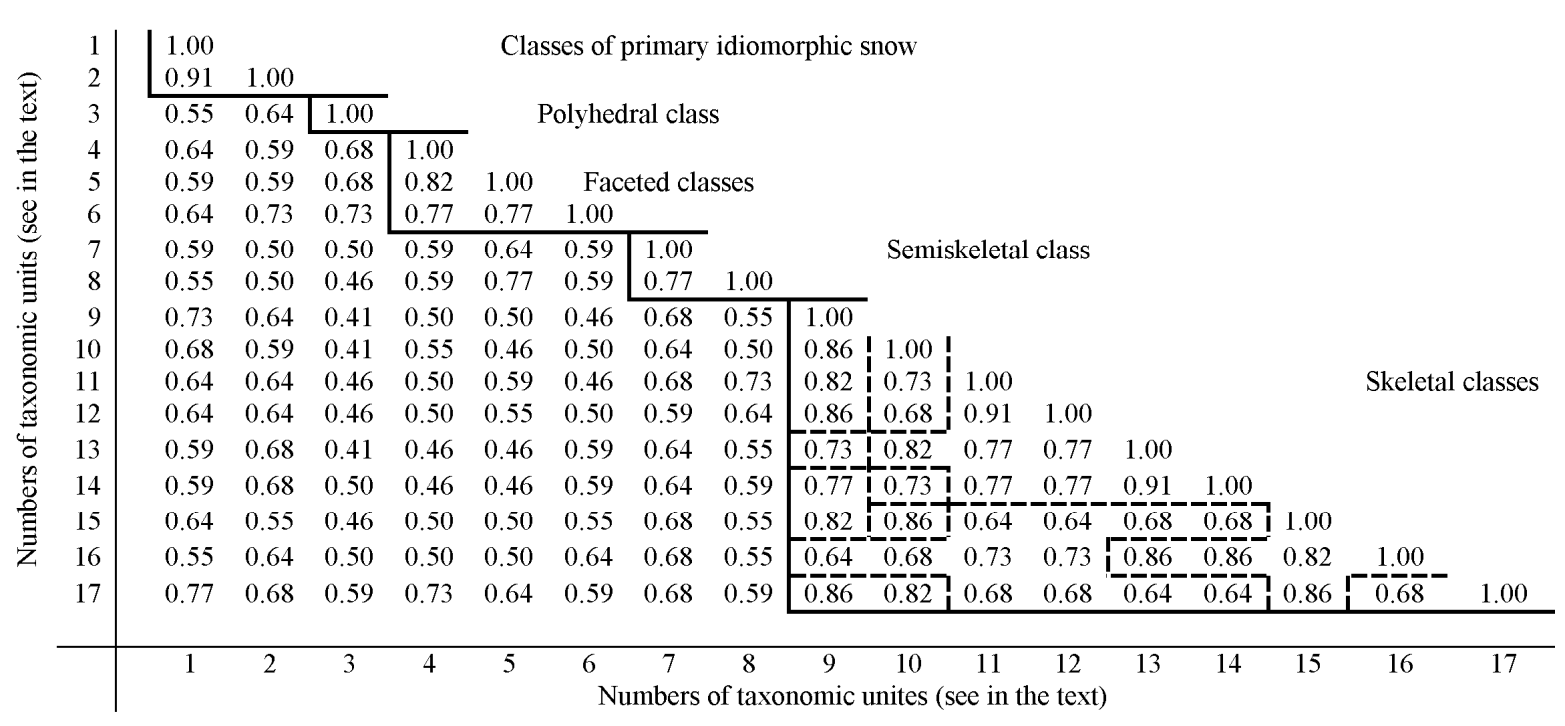

Footnote. Boundaries of crystal form classes are marked in unbroken lines; dotted lines divide the subdivisions of skeletal class complex.

Two described ordinates: classes and types of forms, have been used for construction of the crystal-morphological classification of snow pack (Table 4). This classification makes it possible to extract a much greater wealth of data on the internal processes occurring in the snowpack in comparison with those analytic techniques that are based on traditional concepts concerning the granularity of snow particles.

Table 4. Crystal-morphological classification for snow on the ground

\begin{tabular}{|c|c|c|c|c|c|c|}
\hline $\begin{array}{l}\text { Genetic type of } \\
\text { snow }\end{array}$ & Crystal surface & \multicolumn{2}{|c|}{ Crystal form classes } & $\begin{array}{c}\text { Crystal form } \\
\text { types }\end{array}$ & Symbol & $\begin{array}{l}\text { Conventional } \\
\text { designations }\end{array}$ \\
\hline \multirow{4}{*}{$\begin{array}{c}\text { Primary } \\
\text { idiomorphic } \\
\text { snow (new-fallen } \\
\text { and old snow) }\end{array}$} & \multirow{4}{*}{ Hypidiomorphic } & \multirow{2}{*}{\multicolumn{2}{|c|}{ Faceted }} & Planar & \multirow{3}{*}{$\mathrm{I}_{0}$} & \multirow{3}{*}{$x$} \\
\hline & & & & Columnar & & \\
\hline & & Skeletal & y-crystal & Planar & & \\
\hline & & & & un/d * & $\mathrm{I}_{1}$ & $\rightarrow$ \\
\hline \multirow{4}{*}{$\begin{array}{l}\text { Isomorphic snow } \\
\text { (newly-deposited } \\
\text { and } \\
\text { metamorphosed) }\end{array}$} & \multirow{4}{*}{ Allotriomorphic } & Regelation- & \multirow{2}{*}{ polyhedral } & \multirow{2}{*}{ Isometric } & \multirow{2}{*}{$\mathrm{I}_{0}$} & 0 \\
\hline & & Corrasion- & & & & $\otimes$ \\
\hline & & \multirow{2}{*}{\multicolumn{2}{|c|}{ Sublimation-polyhedral }} & Planar & $\mathrm{III}_{3}$ & 0 \\
\hline & & & & Isometric & $\mathrm{I}_{2}$ & $a$ \\
\hline \multirow{12}{*}{$\begin{array}{c}\text { Second- } \\
\text { idiomorphic } \\
\text { snow } \\
\text { (metamorphosed, } \\
\text { depth hoar) }\end{array}$} & \multirow{12}{*}{ Hypidiomorphic } & \multirow{2}{*}{\multicolumn{2}{|c|}{ Faceted }} & Planar & $\mathrm{II}_{1}$ & = \\
\hline & & & & Columnar & $\mathrm{II}_{2}$ & U \\
\hline & & \multirow{3}{*}{\multicolumn{2}{|c|}{ Semi-skeletal }} & Planar & $\mathrm{II}_{3}^{\mathrm{P}}$ & m \\
\hline & & & & Columnar & $\mathrm{II}_{3} \mathrm{C}_{3}$ & D \\
\hline & & & & $\mathrm{un} / \mathrm{d}$ & $\mathrm{II}_{3}$ & $\Delta$ \\
\hline & & \multirow{3}{*}{\multicolumn{2}{|c|}{ Skeletal mono-crystal }} & Planar & $\mathrm{II}^{\mathrm{P}}{ }_{4}$ & $\nabla$ \\
\hline & & & & Columnar & $\mathrm{II}^{\mathrm{C}}{ }_{4}$ & Q \\
\hline & & & & un/d & $\mathrm{II}_{4}$ & $\triangle$ \\
\hline & & \multirow{3}{*}{\multicolumn{2}{|c|}{ Sectorial }} & Planar & $\mathrm{III}_{1}^{\mathrm{P}_{1}}$ & $\triangleq$ \\
\hline & & & & Columnar & $\mathrm{III}_{1}^{\mathrm{C}}$ & $\triangleq$ \\
\hline & & & & $\mathrm{un} / \mathrm{d}$ & $\mathrm{III}_{1}$ & 으 \\
\hline & & \multicolumn{2}{|c|}{ Plate-like } & Planar & $\mathrm{III}_{2}$ & $=$ \\
\hline
\end{tabular}

*un/d - undivided form types. 
New classification has true evolutionary character, so far as it reflects successive stages of the forms of crystal growth and destruction as a result of persistent process of superposition of their crystal-chemical symmetry and dissymmetry of the hydrothermal fields and of field one-side pressure in snow-pack. It reflects also influence of external environment (the whole soil-snow-air system), which determines the type metamorphic trajectory (columnar, planar or mixed) in some or other snow layer. Thus, this classification may be used as tools instrument for the working out the long-time predictions of transition of snow pack into potentially avalanche-hazardous state. In contrast to the known physical classifications of snow, crystal-morphological classification puts an emphasis on disintegration of secondary idiomorphic snow just because its taxonomic categories make a basis of snow cover structure.

\section{Main Morphological Signs of Growing and Disturbing Crystal}

The crystal-morphological analysis of snow structure requires the use of a statistical set of crystals from each specimen taken from a given snow layer (Kolomyts, 1977, 1984). Main leading morphological attributes of crystals are presented in Table 5 which may be used in the time of structural description of vertical snow profiles. Experience shows that within each set of forms with near visible symmetry there are single crystals with varied elements of faceting. Found here are forms that are both columnar and plate-like and both faceted and skeletal. On the other hand, within the same symmetrical shape, a growing crystal changes its appearance from faceted to skeletal and then to sector and plate-like - in accordance with the trajectory of the sublimation-metamorphic cycle. Most frequently a phase changeover in constructive metamorphism (particularly the transformation of faceted shape to skeletal) is accompanied by a sharp reduction in the symmetry of the crystals (Table 6).

Thus, crystal-morphological analysis of the structure and metamorphism of snow must follow two basic directions: (1) identifying the static parameters of the state of the snow cover and the entire system soil-snow-air by defining the visible symmetry of the crystals from each snow layer; (2) diagnosing the elements of faceting of each monocrystal, establishing on this basis the class and type of form of the crystals and accordingly evaluating the dynamics of the snow structure in time for each layer.

Table 5. Criteria for identifying the classes and types of crystal shapes of sublimation metamorphism in seasonal snow pack

\begin{tabular}{|c|c|c|c|c|c|c|c|}
\hline $\begin{array}{l}\text { Class of } \\
\text { shapes (index) }\end{array}$ & $\begin{array}{l}\text { Type of } \\
\text { shapes } \\
\text { (index) }\end{array}$ & $\begin{array}{l}\text { Axial } \\
\text { relation } \\
c / a\end{array}$ & $\begin{array}{l}\text { Type of facets, } \\
\text { their proportions }\end{array}$ & $\begin{array}{l}\text { Flight of steps } \\
\text { (striation) on facets }\end{array}$ & $\begin{array}{l}\text { Position of growth } \\
\text { steps on facets }\end{array}$ & $\begin{array}{l}\text { Presence of open } \\
\text { cavities, their } \\
\text { dimensions }\end{array}$ & Other features \\
\hline $\begin{array}{l}\text { Faceted planar } \\
\left(\mathrm{II}_{1}\right)\end{array}$ & Planar $\left(\mathrm{II}_{1}\right)$ & $\begin{array}{l}0.3-0.9 \\
(<1)\end{array}$ & $\begin{array}{l}\text { All facets - } \\
\text { characteristic, } \\
\text { basal pre- } \\
\text { dominate }\end{array}$ & Absent & $\begin{array}{l}\text { In the center of } \\
\text { the facet in the } \\
\text { form of small } \\
\text { "waves" }\end{array}$ & Absent & $\begin{array}{l}\text { Basal facets } \\
\text { mirror-like, lines of } \\
\text { ribs highly pronounced }\end{array}$ \\
\hline $\begin{array}{l}\text { Faceted } \\
\text { columnar } \\
\left(\mathrm{II}_{2}\right)\end{array}$ & $\begin{array}{l}\text { Isometric } \\
\text { and } \\
\text { columnar } \\
\left(\mathrm{II}_{2}\right)\end{array}$ & $\geq 1$ & $\begin{array}{l}\text { All facets - } \\
\text { characteristic, } \\
\text { prismatic } \\
\text { predominate }\end{array}$ & As above & $\begin{array}{l}\text { In the internal } \\
\text { sections of the } \\
\text { facet in the form } \\
\text { of a series of } \\
\text { small "waves" }\end{array}$ & As above & $\begin{array}{l}\text { As above; with } \\
\text { presence of piramidal } \\
\text { complications - } \\
\text { "bullet" type }\end{array}$ \\
\hline $\begin{array}{l}\text { Semi-skeletal } \\
\left(\mathrm{II}_{3}\right)\end{array}$ & Planar $\left(\mathrm{II}_{3}^{\mathrm{P}}\right)$ & $\begin{array}{l}0.3-0.9 \\
(<1)\end{array}$ & $\begin{array}{l}\text { Characteristic } \\
\text { bas-al } \\
\text { predominate }\end{array}$ & $\begin{array}{l}\text { Present, slightly } \\
\text { pronounced }\end{array}$ & $\begin{array}{l}\text { Confined to rib } \\
\text { lines and edges of } \\
\text { basal facets }\end{array}$ & $\begin{array}{l}\text { Stepped slightly } \\
\text { pronounced } \\
\text { depressions on } \\
\text { basal plane }\end{array}$ & $\begin{array}{l}\text { Height of stair steps } \\
\text { less than thickness of } \\
\text { basopinacoid, ribs are } \\
\text { straight }\end{array}$ \\
\hline \multirow{3}{*}{ Skeletal $\left(\mathrm{II}_{4}\right)$} & $\begin{array}{l}\text { Columnar } \\
\left(\mathrm{II}_{3}^{\mathrm{C}}\right)\end{array}$ & $\geq 1$ & $\begin{array}{l}\text { Characteristic } \\
\text { prismatic } \\
\text { predominate }\end{array}$ & As above & As above & $\begin{array}{l}\text { Deep cavities, } \\
\text { their volume less } \\
\text { than } 1 / 3 \text { crystal } \\
\text { volume }\end{array}$ & $\begin{array}{l}\text { Crystal massive, facets } \\
\text { and ribs are rectilinear }\end{array}$ \\
\hline & Planar $\left(\mathrm{II}_{4}^{\mathrm{P}}\right)$ & $\begin{array}{l}0.3-0.9 \\
(<1)\end{array}$ & $\begin{array}{l}\text { Vicinal, basal } \\
\text { predominate }\end{array}$ & Well-pronounced & $\begin{array}{l}\text { All lateral facets } \\
\text { intersect in the } \\
\text { form of sharp } \\
\text { straight lines } \\
\text { parallel to basal } \\
\text { ribs }\end{array}$ & $\begin{array}{l}\text { Narrow cavities } \\
\text { between basal } \\
\text { plane and slanting } \\
\text { lateral facets }\end{array}$ & $\begin{array}{l}\text { Base of crystal is } \\
\text { massive, lateral facets } \\
\text { open, main axis } \\
\text { monoclinic }\end{array}$ \\
\hline & $\begin{array}{l}\text { Columnar } \\
\left(\mathrm{II}_{4}^{\mathrm{C}}\right)\end{array}$ & $\geq 1$ & $\begin{array}{l}\text { Vicinal, Lateral } \\
\text { predominate }\end{array}$ & As above & As above & $\begin{array}{l}\text { Deep cavities, } \\
\text { their volume more } \\
\text { than } 1 / 3 \text { crystal } \\
\text { volume }\end{array}$ & $\begin{array}{l}\text { Crystal branchy } \\
\text { (thin-walled), ribs are } \\
\text { rectilinear and } \\
\text { curvilinear, clearly } \\
\text { pronounced }\end{array}$ \\
\hline Sectorial $\left(\mathrm{III}_{1}\right)$ & $\begin{array}{l}\text { Planar } \\
\left(\mathrm{III}_{1}^{\mathrm{P}}{ }_{1}\right)\end{array}$ & $\begin{array}{l}0.3-0.9 \\
(<1)\end{array}$ & $\begin{array}{l}\text { Vicinal, lateral } \\
\text { plate-like } \\
\text { protuberances on } \\
\text { basal plane }\end{array}$ & $\begin{array}{l}\text { Fragmentarily } \\
\text { pronounced on } \\
\text { lateral facets }\end{array}$ & $\begin{array}{l}\text { Steps sparse, } \\
\text { curved, rib lines } \\
\text { uneven }\end{array}$ & $\begin{array}{l}\text { Small cavity from } \\
\text { side of lower } \\
\text { basal plane }\end{array}$ & $\begin{array}{l}\text { Crystal open, needles } \\
\text { rounded, characteristic } \\
\text { cloudiness }\end{array}$ \\
\hline $\begin{array}{l}\text { Plate-like } \\
\left(\mathrm{III}_{2}\right)\end{array}$ & $\begin{array}{l}\text { Planar } \\
\left(\mathrm{III}_{2}^{\mathrm{P}}{ }_{2}\right)\end{array}$ & $0.1-0.2$ & $\begin{array}{l}\text { Vicinal, basal } \\
\text { predominate }\end{array}$ & $\begin{array}{l}\text { Slightly pronounced } \\
\text { on basal plane }\end{array}$ & $\begin{array}{l}\text { Confined to rib } \\
\text { lines and edges of } \\
\text { basal facets }\end{array}$ & $\begin{array}{l}\text { Almost none, } \\
\text { depression on } \\
\text { lower basal plane }\end{array}$ & $\begin{array}{l}\text { Outlines of shapes } \\
\text { irregular, ribs are } \\
\text { curved, crystal is } \\
\text { cloudy }\end{array}$ \\
\hline
\end{tabular}


Table 6. Distribution of crystal shapes of depth hoar at subgroups and kinds symmetry

of sprmitry

Classes of crystal shapes (growth phases) and their types (variants of the evolution trajectory) are unambiguously defined by the metric characteristics of the particles, and also by an entire set of meso- and micromorphological features of the faceting. Various combinations of the enumerated above morphological features can unambiguously characterize both the results of the preceding growth of the crystals and the tendency of their subsequent development. The mesomorphology of crystals allows us to reconstruct the "history" of snow metamorphism during the past winter period and along with micromorphology to predict the most probable (with preservation of the given conditions of the external medium) changes in the snow structure in the future, including those changes which are capable of playing a vital role in the initiation of avalanche hazard. In this lies the certain forecasting value of the crystal-morphological approach to snow analysis.

All facets in a growing crystal are classed as either recurrently growing or nonrecurrent (Bann, 1964; Shafranovsky, 1968; Sheftal, 1973). In recurrent growth the specific profile of the crystal surface is preserved. In 
the opposite case the facets are nonrecurrently growing. Recurrently growing smooth (developed) facets (see Figure 1, $b, c$, and Figure 5, a,b) are referred to as characteristic. They comprise the faceted forms of snow crystals. Such facets are readily recognized by their mirrorlike gloss, absence of striation, large protuberances and caverns, regular geometric outlines, clear definition and rectilinearity of the ribs. A characteristic of the faceted type of formation is the confining of small arc-shaped steps of growth to the internal sections of the facets, where helical dislocations appear. Faceted forms do not have open cavities, that is, they are defectless.

Roughened, or defective, facets should be distinguished from characteristic facets (see Figure1, $e, h$, and Figure $5, f-i)$. They are formed by protuberances (single subcrystals) which are bounded by the narrow sections of smooth facets. Facets which have deviated from their ideal location are termed vicinal. If given step dimensions are identical, then rectilinear, evenly roughened vicinal facets form. When values for step height and width are identical, curvilinear outlines of crystal facets and ribs appear, with unevenly roughened vicinal facets (see Figure 1,e, and Figure 5, $j$ ). Vicinal facets as a rule are characteristic of the skeletal rib forms of depth hoar. The stepped state of these facets when examining them by naked eye or under slight magnification shows up in the form of a characteristic striation.

For columnar crystals of all classes of forms (both faceted and skeletal) one can adopt the axial relation $c / a>1$, for planar and beveled prisms and pyramids, and platelets, $0.3-0.9$ and $0.1-0.2$, respectively. Regarded as skeletal are crystals in which the volume of open cavities occupies not less than one third of the volume of the crystal itself. With a smaller cavity volume or with the presence of small caverns and embryos of skeletal steps the shape is defined as semiskeletal.

Open cavities and caverns are characteristic as a rule for columnar skeletal and semiskeletal crystals. Because highly beveled and planar skeletal and semiskeletal single crystals often almost lack internal cavities, the primary feature of skeletal growth here is represented by the thinning of the initial basopinacoid (planar faceted prism) and the development on its upper facet of a ladder of step-shaped protuberances usually located at a sharp angle with the base (see Figure 1, $g, h$, and Figure $5, f, g$ ). Pseudomonoclinic and pseudotriclinic planar skeletal forms develop in this manner. One can assume that if the height of the growing ladder is less than the thickness of the basopinacoid itself (along axis c), then the form remains semiskeletal. When the relation of these parameters is reversed, a planar crystal shape should be considered skeletal.

Skeletal forms found in progressive development have a well-defined rhythmic stepping on their facets and ribs, thus providing evidence of their zonal structure. Characteristic are the rectilinearity and firmness of the majority of large steps. In the combined development of neighboring side facets, which is intrinsic to intensive columnar growth, the ribs acquire the form of rhythmic nodes of coupling longitudinal and lateral steps (see Figure $5, i$ ). If the vicinal facets developed independently or the growing crystal periodically was subjected to partial dissolution (under conditions of frequent and sharp fluctuations of temperature or compression), then the facets do not touch each other and the side ribs cease to exist as such. This case is more often characteristic of planar skeletal ribs with highly beveled side facets (see Figure $1, h$ ).

In well-metamorphozed snow one finds "aging" and in general "decrepit" single crystals with rounded crests made ragged by the evaporation of basal ribs, with the fragmenting and frequent distorting of steps (see Figure 5, $j$ ). Because often thin semitransparent sectorial protuberances with uneven edges run from the basal facets perpendicularly to their main axis, we refer to such forms of "aging" skeletal crystals as sectorial. At the same time the entire crystal body appears separated into mosaic blocks which transform into single sub-crystals with inlet angles and gas inclusions. There occurs a marked transition from the monocrystal in the center to a polycrystal aggregate on the periphery of the given particle. The single sub-crystals can tilt at $10-30^{\circ}$ from the initial outlines of the crystal. Numerous inclusions of various ingredients give the "aging" single crystals a cloudy tint. The features enumerated point to the process of cleavage in the crystal, causing it to subsequently break up into individual parts. Thus described is the first stage of regressive metamorphism $\left(\mathrm{III}_{1}\right)$. The self-splitting (cleavage) of crystals is very common in rocks (Bann, 1964; Grigoryev \& Zhabin, 1975).

Finally, when sectorial forms split apart, there shape oblique convex thin platelets which almost lose their skeletal microtopography on the basal facets, and are often cloudy, with irregular outlines (see Figure $5, k$ ). Often they can be confused with small planar faceted prisms, but one can differentiate between these forms by the well-defined outlines of the basal perimeter and the pattern of the microtopography on the facets.

\section{Mechanisms of Auto-regulation of Metamorphism in Snow Layers}

The deterministic model of the sublimation-metamorphic cycle is a result of its ultimate schematization (abstraction); therefore, it cannot reflect the whole diversity of metamorphic processes. Such diversity is conditioned by probabilistic character of metamorphic processes exhibited in the mechanisms of their 
auto-regulation (Kolomyts, 1984). Any evolution is at last the auto-regulation (Ashby, 1956). These processes include two basic types of regulation of snow layer metamorphism (Figure 7): (1) self-regulation - "motion" of the layer according to one of the "set" programs for the trajectory of the metamorphic cycle and subsequent growth "buildup" of the structure; (2) their regulation from outside - under the influence of atmospheric perturbations (warming and cooling periods, snowfalls, snowdrift phenomena, etc.) which transfer the layer from one program of development to another and thereby accelerate or, conversely, retard the overall rate of metamorphism. The key task in analyzing the evolution of a snow pack is clearly demarcating these two basic processes because only then is it possible to arrive at a practicable forecast of the critical state of the structure of some layer.

The mechanisms of auto-regulation of snow layers may be traced in the transitions of each one of them from one state to another, that is, when comparing structural changes which have occurred during a given step of time. Such transitions in principle are probabilistic in character, this being due to the non-uniform growth of different crystals of the same age. The "motion" of the first growth generation of depth hoar crystals on the trajectory of the sublimation-metamorphic cycle is accompanied by a successive increase in the number of classes of crystal forms to some maximum values. In this, however, the transformation of the layer does not stop even under conditions of a steady-state external medium. With the appearance of a substantial quantity of skeletal forms, there begin cycles of growth buildup of sets of single crystals. In addition, when in a state in which skeletal forms of "mature" depth hoar dominate, the layer during two or three successive steps may transition to a new program of re-crystallization if an abrupt, stable change in the conditions of the external medium has occurred.

The processes of auto-regulation of metamorphism of snow layers are disclosed with the aid of matrices and graphs of the probabilities of transitions of crystal classes and types of forms into others during a given series of time steps (Table 7, Figure 7). Methods of calculation of such transitions are described in (Ashby, 1956). Modeling was based on the materials of regime surveys carried out by the authors at experimental test site in middle taiga of West Siberian (Kolomyts, 1976).
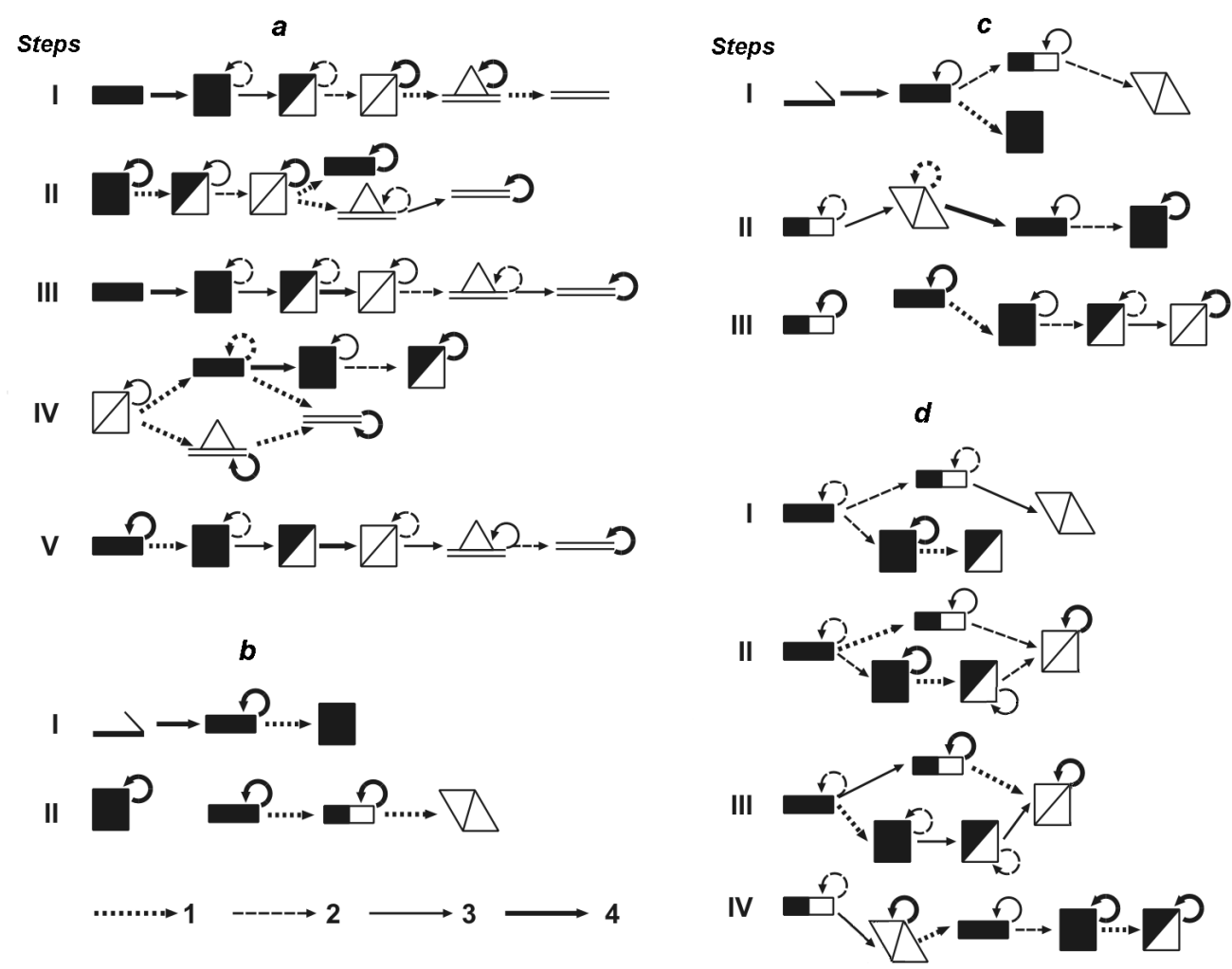

Figure 7. Stochastic structural models of the self-regulation in the sublimation metamorphism of snow layers

Models of self-regulation (self-development): $a-$ a complete columnar program; traced are the linear cycle of transformations of crystal shapes and two cycles of growth complexity in the structure of the layer; $\boldsymbol{b}$ incomplete planar program; columnar faceted forms of skeletal single crystals are not produced. 
Models of the regulation of metamorphism from outside: $c$ - polygenetic program with one irreversible perturbation from the planar algorithm to the columnar; $d$ - polygenetic program with simultaneous planar and columnar crystal growth; planar skeletal growth begins earlier and advances more rapidly than the columnar. Probabilities (frequency) of transitions of one form classes into another: $1-0.01-0.25 ; 2-0.26-0.50 ; 3-$ $0.51-0.75 ; 4-0.76-1.00$.

1 step $\approx 25-35$ of days. The remaining symbols are defined on Figure 4 and in Table 6 .

\subsection{The Process of Self-regulation in the Metamorphic Cycle}

In the lower snow pack layers, which usually have the highest rate of re-crystallization, the assemblage of crystals over the period of the first two steps traverses practically the entire elemental chain of transformations in accordance with the columnar algorithm (see Figure 7a). "The center of gravity" of the transitions is concentrated in the skeletal forms. Further transformations of snow layer are associated with the growth build-up of the capacity of classes of crystal forms, the process of which is fluctuating and cyclical in character externally resemble the "population waves" known from the evolutionary biology (Odum, 1983). Each cycle begins with the breaking of the elemental chain after the stages of faceted forms. All of the most developed faceted crystals are depleted in the process of intensive skeletal growth. There occurs a shortage of faceted crystals ready for transition to a next stage, causing a break in the chain. This shortage is covered by the formation of a new growth generation of crystals, beginning with planar faceted prisms, partially replacing skeletal and plate-like forms (the second and fourth steps in Figure 7a).

Table 7. Example of matrixes of real trans formation in form of depth hoar crystals in any layer of snow pack $(A)$ and of trans formation crystal forms in the same layer during Markov's process $(B)$. Step length is 25-35 days

\begin{tabular}{|c|c|c|c|c|c|c|c|c|c|c|c|c|c|c|}
\hline & & & A & & & & & & & & & 8 & & \\
\hline$\downarrow$ & D & 】 & $\Delta$ & $\square$ & $\triangleq$ & $=$ & & $\downarrow$ & n & $\square$ & $\Delta$ & $\square$ & 至 & $=$ \\
\hline 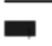 & 0 & $\mathrm{~J}$ & 0 & 0 & 0 & 0 & & $\overline{0}$ & 0 & $\mathrm{~J}$ & 0 & 0 & 0 & 0 \\
\hline & 1.00 & 3.49 & 0 & 0 & 0 & 0 & & $\bar{\square}$ & 1.00 & 3.49 & 0 & 0 & 0 & 0 \\
\hline 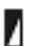 & 0 & 3.51 & 0.38 & 0 & 0 & 0 & iston & & 0 & 3.51 & 0.38 & 0 & 0 & 0 \\
\hline ⿹ & 0 & J & 0.62 & 0.86 & 0 & 0 & & $\emptyset$ & 0 & J & 0.62 & 0.86 & 0 & 0 \\
\hline 은 & 0 & J & 0 & 0.14 & 0.80 & 0 & & 드 & 0 & J & 0 & 0.14 & 0.80 & 0 \\
\hline$=$ & 0 & J & 0 & 0 & 0.20 & 1.00 & & $=$ & 0 & J & 0 & 0 & 0.20 & 1.00 \\
\hline$\downarrow$ & n & $\square$ & $\Delta$ & $\square$ & $\hat{=}$ & $=$ & & $\downarrow$ & n & $\square$ & $\Delta$ & ด & 으 & $=$ \\
\hline 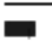 & 0 & J & 0 & 0 & 0 & 0 & & $\overline{0}$ & 0 & 0 & 0 & J & 0 & 0 \\
\hline & 0 & 3.88 & 0 & 0 & 0 & 0 & & & 0.49 & 0.24 & 0 & J & 0 & 0 \\
\hline$\Delta$ & 0 & 3.12 & 0.71 & 0 & 0 & 0 & Nstep & 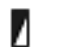 & 051 & 0.44 & 0.14 & J & 0 & 0 \\
\hline$\square$ & 0 & J & 0.29 & 0.80 & 0 & 0 & & $\square$ & 0 & 0.32 & 0.77 & 3.74 & 0 & 0 \\
\hline ค & 0 & J & 0 & 0.11 & 0.40 & 0 & & 气 & 0 & 0 & 0.09 & J.23 & 0.64 & 0 \\
\hline$=$ & 0 & J & 0 & 0 & 0.60 & 1.00 & & $=$ & 0. & 0 & 0. & J.33 & 0,36 & 1.00 \\
\hline$\downarrow$ & - & I & $\Delta$ & D & 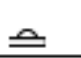 & $=$ & & $\downarrow$ & - & $\square$ & 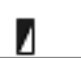 & Ø & 스 & $=$ \\
\hline 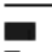 & 0.75 & J & 0 & 0 & 0 & 0 & & $\bar{\square}$ & 0 & 0 & 0 & 3 & 0 & 0 \\
\hline & 0.25 & 3.28 & 0 & 0 & 0 & 0 & & & 0 & 0 & 0 & J & 0 & 0 \\
\hline$\Delta$ & 0 & 3.72 & 0 & 0 & 0 & 0 & V step & & 0 & 0 & 0 & J & 0 & 0 \\
\hline ด & 0 & J & 1.00 & 0.42 & 0 & 0 & & $\square$ & 026 & 0.20 & 0.12 & 3.10 & 0 & 0 \\
\hline 스 & 0 & J & 0 & 0.58 & 0.62 & 0 & & 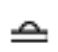 & 026 & 0.27 & 0.18 & 3.16 & 0.03 & 0 \\
\hline$=$ & 0 & J & 0 & 0 & 0.32 & 1.00 & & $=$ & 0.47 & 0.53 & 0.70 & 0.74 & 0.97 & 1.00 \\
\hline
\end{tabular}

The "wave" of the crystal shortage in each cycle traverses over the entire elemental chain to cause a series of corresponding reactions in each of its links. The cycle ends with the complete restoration of the elemental chain and renewal of intensive skeletal growth (third and fifth steps in Figure 7a). In each cycle of crystal buildup the snow layer returns as it were to the initial stages of constructive metamorphism. The periodic "rejuvenation" of the crystal assemblage of the snow layer, due exclusively to its self-development, may substantially change the mechanical properties of the snow even with unchanged external conditions.

The "waves" of self-regulation are the phenomenon of the stabilizing selection of crystal forms, which 
contributes to elongation of the period of constructive metamorphism in snow layer and hinder from their transition to regressive metamorphism by cycles of periodical age-specific build-up of its structure. The effect of the stabilization is traced while comparing real steps in the evolution of the snow layers (see Table 7, $A$ ) with the steps of a computational "Markov's machine" (Harbaugh \& Bonan-Carter, 1970), where all relative frequencies of the transitions are specified according to the first step (see Table 7, B). The steps of a Markov regulating operation are obtained by sequentially multiplying the matrix by itself. This computation makes it possible to forecast the final state of the system with the initial frequencies of transitions preserved in all steps.

In a Markov regulating operation the snowpack should attain states towards the end of winter when the probabilities of final crystal forms and of transitions to these forms become almost identical and close to 1 . In facts, thanks to the stabilization effect, the layers usually do not attain these states. The difference in frequencies of transitions between the real and the Markov's processes of self-regulation of metamorphism is that corrective measure which should be introduced when forecasting the structure of the snow layer at each subsequent time step.

Because the growth of skeletal crystals directly from planar faceted prisms is characteristic of the planar variant of metamorphism, a significant quantity of skeletal forms may appear in a month (see Figure 7b). Columnar faceted forms grow extremely slowly, gradually lose the base of their development and degrade. The planar variant of growth differs from the columnar by the large nonuniformity of crystal growth in the development of crystals of the same growth generation, this conforming to the more complex hydrothermo-dynamic fields of snow. Dominant in this case are the prolonged stabilization of forms and the weak intensity of the transitions, thanks to which the elemental chain of the plot is preserved over several steps.

\subsection{Regulation of Snow Metamorphism from Outside}

The processes of self-regulation in the snowpack layers periodically become complicated by external perturbations, with subsequent restructuring of the current program of structure transformations from planar to columnar or the reverse. External regulation is responsible for adaptive selection of crystal forms in snow layers. The most frequent type of perturbations is characteristic of layers which have remained a long time near the snow surface during severe cooling and sudden fluctuations in temperature and then were buried under new thick layers of snow and located in more moderate temperature conditions. A similar effect may be produced also by prolonged stable warming. Such external perturbation is registered in the second step of transitions (see Figure 7, c). A sudden perturbation in the algorithm causes the breakup and subsequent extinction of the planar chain of development. The number of beveled skeletal forms is reduced catastrophically, and the "center of gravity" of the transitions displaces to faceted columnar prisms which already reveal signs of skeletal growth. However, snow layer "thrown back" two entire steps by perturbation (from skeletal to faceted columnar) may never attain the state of "mature" depth hoar.

Often observed in the upper layers of the snow pack are mixed variants of metamorphism with simultaneous development of both planar and columnar types of crystal forms. When the temperature field in the snow layer is manifestly nonsteady state, the planar chain of transitions significantly outstrips the columnar (see Figure 7, $d$ ). Subsequently when the columnar types reach the skeletal phase of growth both chains converge. Pulsating "waves" of shortages of forms alternately pass through each chain, causing corresponding attenuation and amplification of the transition frequencies. With an overall increase in temperature at the end of winter the planar chain usually decomposes and the "center of gravity" of the transitions shifts to columnar types of forms with a slowing of the processes of metamorphism.

On the whole if the transition of a snow layer from the columnar program of crystal growth to the planar somehow accelerates the process of "maturing" of the depth hoar, then a reverse shift from the planar algorithm to the columnar leads to slowing of this process. On its basis one should correct for the effect of external perturbations when predicting the structure of different layers of the snow pack.

\section{Systemic Organization of Snow Pack and Metamorphic Formation of Snow Cover}

\subsection{Quantitative Evaluation of Snow Layer Metamorphism}

In terms of the systems theory, the structure of each genetic layer of snow pack is determined by diversity of crystal shapes and their various deviations from the most stable shape (some etalon state). Such etalon, as has already been shown, is the skeletal stage of their growth, when superposition of the symmetries of growing crystal and environment reaches its culmination. Deviation of the crystal community in snow layer from the etalon was expressed via the measure of its situational disordering. To this effect, each layer (SL) was presented as a row vector, the elements (variables) of which were different classes of crystal shapes (see above) 
corresponding to certain stages of their growth:

$$
\left(\mathrm{I}_{1,2} \mathrm{U} \mathrm{II}_{1} \mathrm{U} \mathrm{II}_{2} \mathrm{U} \mathrm{II}_{3} \mathrm{U} \mathrm{II}_{4} \mathrm{U} \mathrm{III} \mathrm{I} \mathrm{III}_{2}\right) \leftrightarrow \mathrm{SL}
$$

Here, $U$ and $\leftrightarrow$ are the signs of union and equivalence of sets. Stages are certain microstates of crystal shapes, while layer development phases characterize the macrostates of the SL set.

Disordering of the system is the measure of misalignment of state $i$ of each of its elements with its etalon state $x_{i \mathrm{ee}}$. This measure tends to zero at $x_{i} \rightarrow x_{i \mathrm{et}}$. Since the etalon of orderliness is known beforehand, the trajectory of object's "movement" to its etalon may be considered as a program of its gradual changes (evolution). In this case, it will be the program of snow sublimation metamorphism.

Our observations and calculations have shown that the average optimum of orderliness of snow layers

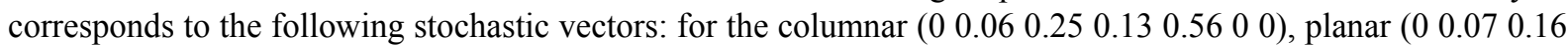

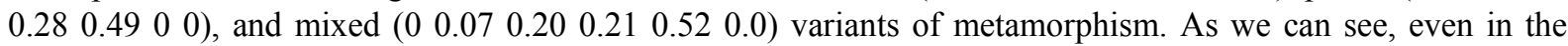
optimum of its situational orderliness, the layer cannot be entirely composed by skeletal crystals.

The variants of metamorphism differ in the boundaries of the etalon region and the optimums of orderliness. When winter is more continental, more crystals are involved in skeletal growth for the layer to reach the etalon region and the progressive transformations of snow structure (the period of constructive metamorphism) are longer. The optimum vector of layer ordering characterizes the "goal" of snow evolution mentioned above. When moving towards or away from this goal, the layer at each step has certain disordering relative to its optimum etalon. The parameters of such disordering (misalignment) will be the values of probability difference $P_{i j}-P_{\text {et } i}$ for each variable of the vector: the class of crystal shapes. In accordance with methodical developments (Gorsky, Gorskaya, 1970), the total disordering of snow layer $\bar{O}(\mathrm{SL})_{i}$ can be determined by the Euclidean distance:

$$
\bar{O}(S L)_{i}=\sqrt{\sum_{j=1}^{n}\left[\mu_{i j}\left(P_{i,}-P_{e t j}\right)\right]^{2}}
$$

where $P_{i j}$ is the probability (occurrence) of class $i$ of crystal shapes in layer $j, P_{\mathrm{et} i}$ is the etalon value of probability of the same class at the optimum state of SL, and $\mu_{i j}$ is the weight factor characterizing the importance of this misalignment. This factor was obtained by calculations on the basis of implication relations between SL set elements.

\subsection{Regional Types for Metamorphic Formations of Snow Cover}

The measure of snow pack (SP) disordering is a function of relative thickness of composing layers $\left(T_{1}, T_{2}, T_{3}, \ldots\right.$, $\left.T_{m}\right)$ and their disordering value $\left(\bar{O}(\mathrm{SL})_{1}, \bar{O}(\mathrm{SL})_{2}, \bar{O}(\mathrm{SL})_{3}, \ldots, \bar{O}(\mathrm{SL})_{m}\right)$. Since we deal with the probability parameters of layer structure, it would be advisable to express snow pack disordering in information units. This disordering may be called entropy, because it is calculated in accordance with the Shannon's concept of uncertainty as a logarithmic function (Gorsky \& Gorskaya, 1970). The expression for the measure of snow pack disordering $\bar{O}(\mathrm{SP})_{k}$ is as follows (in bits):

$$
\bar{O}(S P)_{k}=\sum_{i=1}^{m} T(S L)_{i} \cdot \log _{s}\left[\bar{O}(S L)_{i}+1\right]
$$

This measure may serve as a generalized formal criterion: the integral index of the degree of snow cover sublimation metamorphism. The maximum values of snow pack disordering correspond to the state of its genetic layers when the $\bar{O}(\mathrm{SL})_{i}$ value is maximal, while the minimum values are at $\bar{O}(\mathrm{SL})_{i} \rightarrow 0$.

In practice, it is more convenient to use the snow pack re-crystallization coefficient $(R C)$, which is derived from $\bar{O}(\mathrm{SP})$ and expressed in unit fractions (Table 8). At $R C=1$, the entire snow pack is in the optimum of skeletal phase state, i.e., characterized by the maximum degree of sublimation metamorphism, while at $R C=0$ it is characterized by actual absence of the traces of constructive metamorphism, when the $\bar{O}(\mathrm{SL})_{i}$ value is maximal along the entire profile. 
Table 8. Conversion of the measure of snow pack disordering into the value of its re-crystallization coefficient expressed in unit fractions (for loose and weakly packed snow)

\begin{tabular}{cccc}
\hline Measure $\bar{O}(\mathrm{SP})$, in conventional bits, under metamorphism versions & \multirow{2}{*}{ Re-crystallization coefficient $(R C)$} \\
\cline { 1 - 3 } planar & mixed & columnar & 0 \\
0.418 & 0.326 & 0.280 & 0.1 \\
0.337 & 0.295 & 0.253 & 0.2 \\
0.336 & 0.262 & 0.226 & 0.3 \\
0.296 & 0.230 & 0.197 & 0.4 \\
0.251 & 0.197 & 0.163 & 0.5 \\
0.210 & 0.165 & 0.141 & 0.6 \\
0.170 & 0.132 & 0.113 & 0.7 \\
0.126 & 0.099 & 0.084 & 0.8 \\
0.084 & 0.067 & 0.056 & 0.9 \\
0.041 & 0.033 & 0.028 & 1.0 \\
0 & 0 & 0 &
\end{tabular}

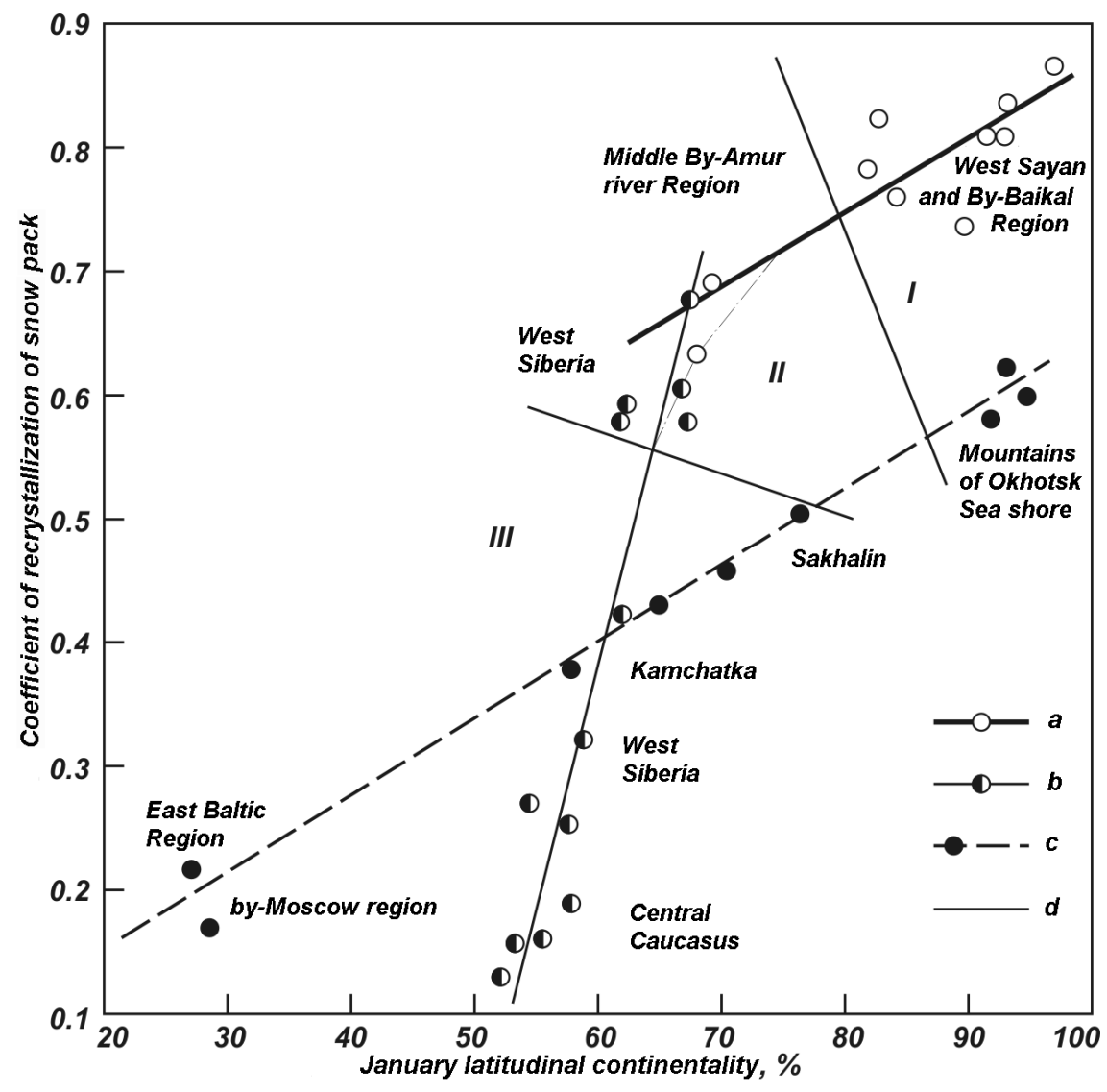

Figure 8. Empirical correlation connections of snow pack re-crystallization coefficient (in unit fractions) with the value of the January latitudinal continentality (for dry loose and dense snow of forest plain and mountain territories)

Regions: $a$ - extracontinental regions of East Siberia and the Far East; $b$, inland territories with enhanced continentality (West Siberia, Central Caucasus, etc.); $c$ - East-European plain, as well as insular, peninsular and coastal regions of the Far East with the lower winter continentality; $d$ - the boundaries between the variants of snow sublimation metamorphism: I, planar; II, mixed; III, columnar. 
Comparison of the obtained structural characteristics of snow profiles from different regions of North Eurasia has shown that the maximum regional differences (zonal, longitudinal-sectorial and altitudinal-zonal) in the degree of snow cover metamorphism must be associated with the winter latitudinal climate continentality. The latter is expressed through the value of January temperature deviation in a given place from the mean January temperature of the respective circle of latitude (Rubinshtein, 1953; Polozova, 1954).

The studies that we have performed in the plain and mountain, mainly forest, regions of Siberia and the Far East yielded the correlation connections between the degree of sublimation metamorphism (parameter $R C$ ) of dry loose and weakly packed snow and the value of the January latitudinal continentality (Figure 8). The relative error of calculations based on these dependences does not exceed 2-14\%. Small-scale maps of the degree of sublimation metamorphism of snow cover in Asian Russia (Figure 9) and North America, mainly Canada and Alaska (Figure 10), were constructed on the basis of these correlation connections by the data of multiyear val-ues of the mean January temperature. The maps demonstrate the background values of snow re-crystallization that may be anticipated in some or other regions, which can be used, e.g., in development of more perfect schemes of geographical demarcation of mountain territories by the level of avalanche danger.

Snow cover is most re-crystallized in the extracontinental regions of Central Yakutia, northeastern and middle Siberia, the Baikal region, intermountain valleys of the Amur River basin (Priamurye) and Ocean-side (Primorye), as well as in the central regions of Canada adjoining the Hudson Bay $(R C=0.8-0.9)$. A somewhat lower degree of metamorphism $(R C=0.6-0.7)$ is characteristic of the territories of Sakhalin, the Altai-Sayan highlands, and the northwest Canada. Sublimation metamorphism is much less pronounced in the taiga regions of West Siberia, the Ural and Pre-Ural region, on the continental shores of the Seas of Okhotsk and Japan, as well as in Alaska and in the southwest part of Canada (RC varies from 0.2-0.3 to 0.5-0.6). Finally, the ocean shores of Kamchatka and Alaska, as well as the least continental forest regions of the Russian Plain, the Caucasus and the Alps, where the January latitudinal continentality is less than $50 \%$, are characterized by sublimation re-crystallization close to zero.

The upper mountain belts in various regions, often quite distant from each other, in contrast to plain and low-mountain territories, much less differ in snow structure, which is in agreement with their known reciprocal relative similarity in winter climate conditions that are generally subcontinental. In the bald-peak (mountain tundra) belts of the West Sayan, Polar Urals and Khibins, snow profile structures are very similar to each other, with snow pack re-crystallization coefficients of about $0.3-0.4$.

On the increase in the maximum (prevernal) snow depth from 10-30 to $120-140 \mathrm{~cm}$, the RC parameter decreases from $0.85-0.90$ to $0.35-0.35$ and less. It corresponds to the transition from drastically continental regions with little snow to the territories of mild winters with much snow (Richter, 1948). Thus, the re-crystallization coefficient of snow pack is its complex structural parameter reflecting the basic climate-forming factors and the cold season processes.

There are four distinct meridian sectors distinguished on the basis of $R C$ parameter and the gradients of its variations on the territory of Russia (see Figure 9). The following climatic regions correspond to these sectors according to (Alisov, 1956): (1) Atlantic-continental forest (together with Atlantic-Arctic) region; (2) continental forest West-Siberian Region (together with the Altai and Sayan mountain Region); (3) continental forest East-Siberian Region (together with the Siberian Region of the Subarctic belt and the Monsoon forest Region); and (4) Pacific forest Region.

Thus, four basic regional types of snow cover megastructure (sublimation-metamorphic formations) with the respective values of snow re-crystallization coefficient can be distinguished for the temperate and high latitudes (Table 9). On the territory of Russia, these are the western suboceanic type of megastructure (meridian climatic sector 1), the western subcontinental type (sector 2), the continental type (sector 3 ), and the eastern suboceanic and oceanic types (sector 4). The eastern variants of suboceanic and subcontinental types of snow cover megastructure have a slightly higher degree of snow re-crystallization compared to the western variants, which is due to the effect of winter continental monsoon in the coastal regions of the Far East. 


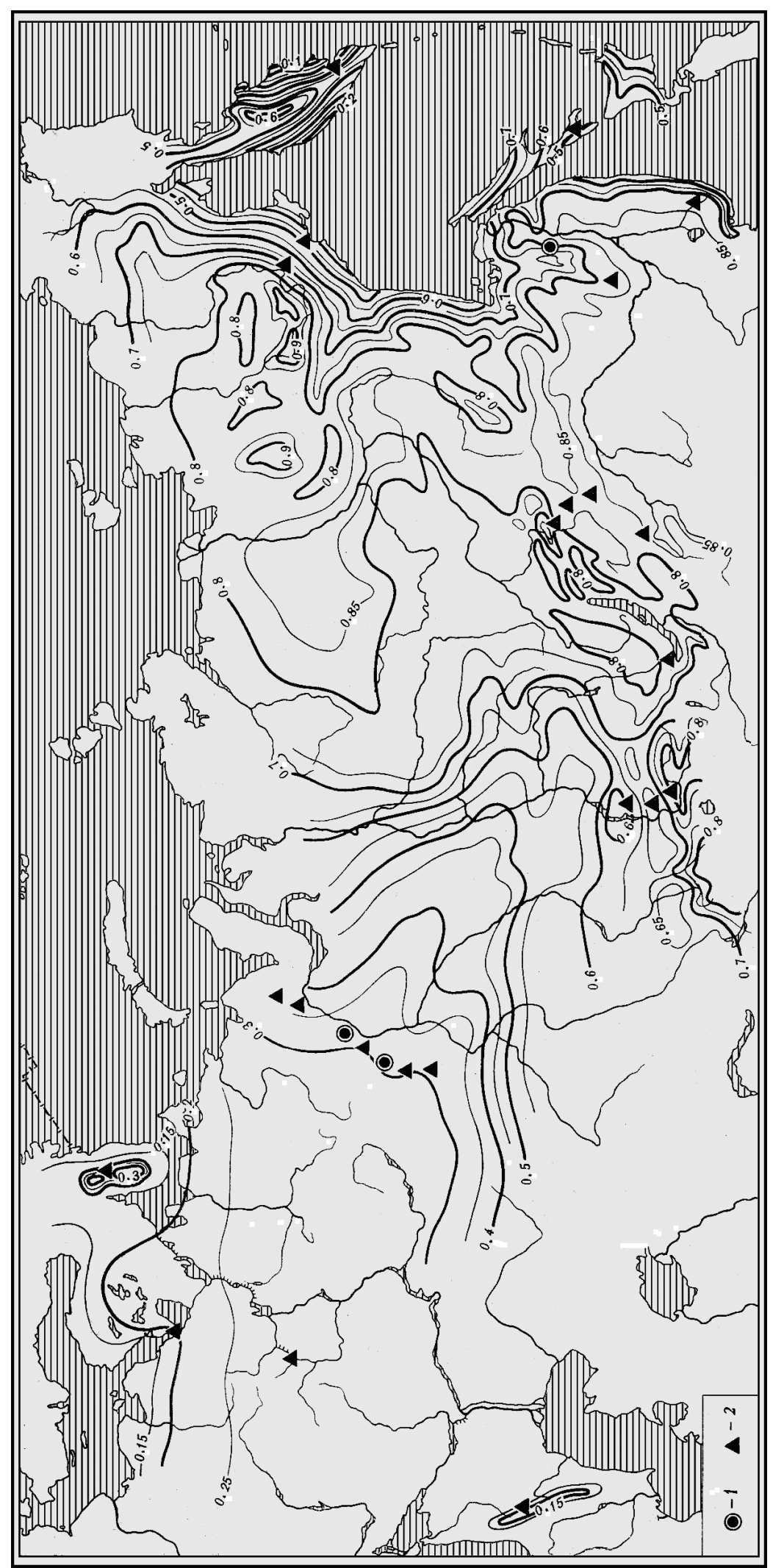

Figure 9. The map of the degree of sublimation metamorphism of snow cover of taiga, forest tundra, mixed, broad-leaved and small-leaved forests on the territory of Russia

$0.1,0.2,0.3, \ldots-$ the isolines of snow pack re-crystallization coefficient. The regions where the author has performed structural snow studies: 1 , stationary; 2 , route. 


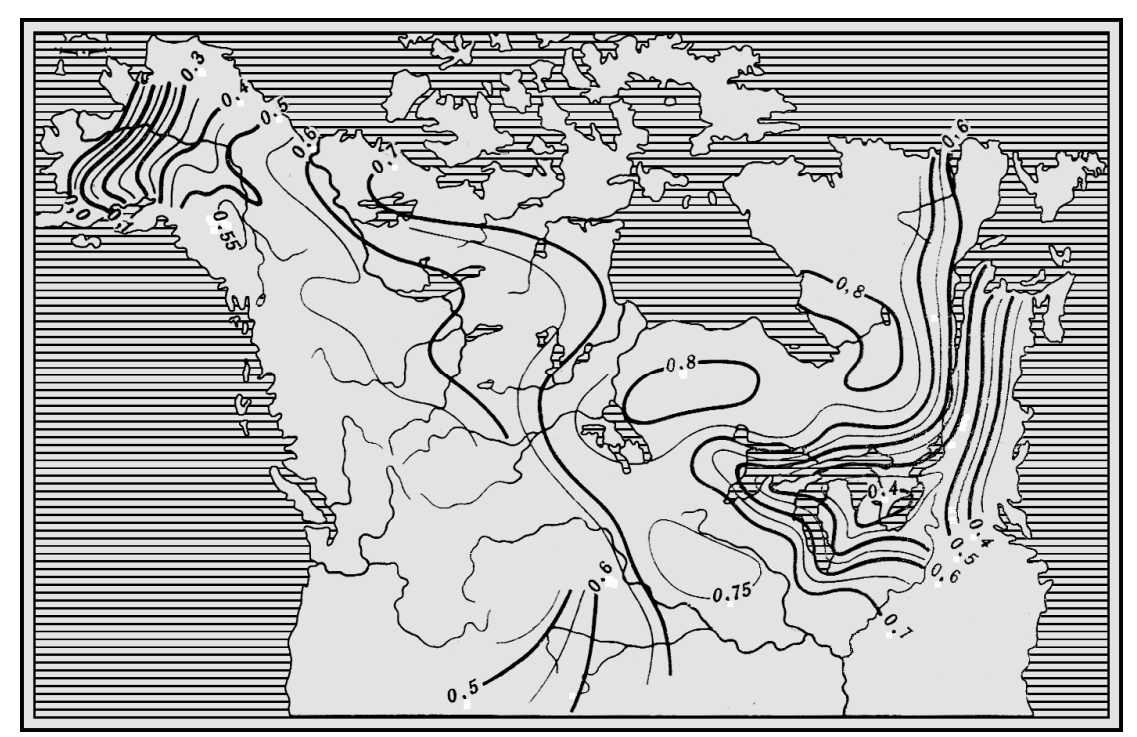

Figure 10. The map of the degree of sublimation metamorphism of snow covers on forest, forest-tundra and forest-steppe territories of North America. Meanings are as Figure 9

Table 9. Values of re-crystallization coefficient of snow pack for different types and subtypes of metamorphic formation of snow cover

\begin{tabular}{ccc}
\hline \multirow{2}{*}{ Formation types } & \multicolumn{2}{l}{ Formation subtypes } \\
\cline { 2 - 3 } & western & eastern \\
\hline Oceanic & $0-0.05$ \\
Suboceanic & $0.1-0.2$ & $0.3-0.6$ \\
Subcontinental & $0.1-0.3$ & $0.4-0.7$ \\
Continental & \multicolumn{2}{c}{$0.7-1.0$} \\
\hline
\end{tabular}

\section{Conclusion}

(1) The crystal-morphological and symmetry studies of snow packs made it possible to go deep into the essence of mechanisms of sublimation metamorphism, to estimate the role of internal and external factors of snow re-crystallization and, finally, to arrange the conceptions of milestones of this re-crystallization. It is worked out the deterministic and probability models describing the sublimation-metamorphic evolution cycle of seasonal snow cover, the polymorphic variants of this cycle and processes of internal and external auto-regulation of metamorphism. Self-development crystal communities in snow layers is main process of structure transformation of season snow.

(2) Evolution of each snow layer is a directed process of appearance and disappearance of successively alternating ways of spatial ordering of crystal forms under energetic influence of snow environment as a necessary condition of this evolution. The origins of the mechanisms of directed evolution of snow layers are concentrated in the crystal-medium (vapor) and crystal-crystal systems.

(3) Diversity of snow structures is caused both invariant directed process of stage development of crystal forms and probabilistic dynamic of crystal communities exhibited in the mechanisms of their auto-regulation. Accordingly snow cover can be considered as the evolutionary-adaptive glaciosystem. Deterministic and stochastic modeling of metamorphic processes opens a way to long-time prediction of snowpack potentially avalanche-hazardous state. Internal and external waves of metamorphism auto-regulation are inevitably associated with periodical transitions of snow layers into the state of "mature" depth hoar (mass development of skeletal forms).

(4) The proposed crystal-morphological and symmetry methods of snowpack structure analysis make it possible to extract a much greater wealth of data on the internal processes occurring in the snowpack in comparison with those analytic techniques that are based on traditional concepts concerning the granularity of snow particles. 
In fact excluded from consideration in the granulometric approach to analysis of snow structure is such a vitally important characteristic as the form of growing or vaporizing crystals (and consequently, the quantitative measure of the quality of the structure), without which it is simply meaningless to discuss the evolution of snow and the directionality of its metamorphism. The crystal-morphological and symmetry parameters examined above and not the dimensions of the grains and their contacts should serve as the main guiding signs of the different levels of metamorphism (evolution) of snow and as the basis for predicting its potential structural changes. This postulation follows from the fundamental principles of contemporary crystallography and the theory of metamorphism.

(5) The essence of metamorphic transformations of snow is not in the diffusion and mechanical redistribution of solid material in a given volume of snow but in the staged changeover in the various means of spatial order in crystallized material, this being manifested first of all in two morphological signs: (1) in the staged changeover in shapes of growth or dissolution (vaporization) of the crystals; (2) in the change in their external (geometric) symmetry through successive deviation from their ideal (crystal-chemical) symmetry. The granulometric characteristics are only accessory and, moreover, are ambiguous parameters describing the dynamics of the processes of re-crystallization, and hence using them is a necessary but altogether insufficient condition for the quantitative evaluation of the structure of snow.

(6) The crystal-morphological and symmetry features of snowpack structure are not only purely structural in character. Numerous investigations have proved that morphology of crystals discloses definite linkages with the mechanical properties of snow and with meteorological conditions - the very characteristics that are taken into account as avalanche-formation factors in engineering computations.

(7) New morphological dynamic classification of snow crystals in snow cover has been worked out by author on the base of evolutionary conception of snow sublimation metamorphism. For the first time the method of numerical taxonomy was used for systematization, making it possible to represent the basic property of a crystal (shape) in quantitative form. Two categories of crystal forms have been picked out by matrixes of coefficients of similarity of the taxonomic units: classes and types of forms. The first category reflects the invariant aspect of snow sublimation metamorphism and the second one - the hydrothermal conditions of this process in each layer of the snowpack, that is the polymorph variants of united sublimation-metamorphic cycle. Type of crystal form is closely connected with the degree of winter continentality and the position (on the depth) of given layer in the snowpack as well.

(8) The structural transformations of snow cover demonstrate certain correlation connections with the zonal-regional climatic factors. The dependence of the integral measure of snow pack sublimation metamorphism on latitudinal winter continentality is most pronounced. These connections were a basis for constructing the maps of the degree of snow cover metamorphism in the taiga and adjacent forest, forest-tundra and forest-steppe regions of Russia and North America. Climatic interpretation of the maps revealed the largest structural units of snow cover: the regional megatypes of its sublimation-metamorphic formations.

\section{References}

Alisov, B. P. (1956). Klimat SSSR. Moskva, M.: Izdatelstvo MGU (in Russian).

Armand, D. L. (1975). Nauka o landshaphte. Moskva, M.: Nauka (in Russian).

Ashby, W. R. (1956). Introduction to Cybernetic. London, L: Macmillan \& Co.

Bailey, N. T. J. (1967). The mathematical approach to biology and medicine. London - New York - Sydney, LNYS: John Wiley and sons.

Bann, Ch. (1964). Crystals. Their role in nature and in science. New-York and London, NYL: Academic press.

Bartelt, P., Buser O., \& Sokratov S. A. (2002). A nonequilibrium treatment of heat and mass transfer in alpine snow covers. Cold Region Science and Technology, 35(3), 219-242.

Bartelt, P., \& Lehning M. (2002). A physical SNOWPACK model for Swiss avalanche warning. Part I; numerical model. Cold Region Science and Technology, 35, 123-145. http://dx.doi.org/10.1016/S0165-232X(02)00074-5

Bozhinsky, A. N., \& Losev, K. S. (1978). Osnovy lavinovedeniya. Leningrad, L.: Gidrometeoizdat (in Russian).

Bozhinsky, A. N., Nazarov, A. N., \& Chernous P. A. (2002). A probabilistic model of snow avalanche: origin and motion. Data of Glaciol., 93, 79-84.

Brown, R. L., \& Edens, M. Q. (1991). On the relationship between neck length and bond radius during com- 
pression of snow. J. Glaciol., 37(126), 203-208.

Brun, E., David, P., Sudul, M., \& Brunot, G. A. (1992). A numerical model to simulate snow-cover stratigraphy for operational avalanche forecasting. J. Glaciol., 38(128), 13-22.

Chernov, R. A. (2003). Vliyanie temperaturnogo rezhima snezhnoy tolshchi na obrazovanie gorizontov razry-hleniya. Materialy glyatciologicheskih issledovani, 94, 100-102 (in Russian).

Colbeck, S. C. (1982). An overview of seasonal snow metamorphism. Reviews of Geophys. and Space Phys., 20(1), 45-61. http://dx.doi.org/10.1029/RG020i001p00045

Colbeck, S., Akitaya, E., \& Armstrong, R. (1990). The International Classification for Seasonal Snow on the Ground. Intern. Commission of Snow and Ice of Internat. Assoc. of Scientif. Hydrology. Working group on Snow Classification.

Curie, P. (1908). Sur la symmetrie dans les phenomenas physiques. Curie P. Oeuvres. Paris, 118-141.

Durand, Y., Brun, E., \& Merindol L. (1993). A meteorogical estimation of relevant parameters for snow model. Annals of Glaciol., 18, 65-71.

Edens, M. Q., \& Brown, R. L. (1991). Changes in microstructure of snow under large deformation. J. Gla-ciol., 37(126), 193-202.

Fierz, Ch., Armstrong, R. L., Durand, Y., et al. (2009). The International Classification for Seasonal Snow on the Ground. IACS, vi +67 pp. (UNESCO, IHP-VII, Technical Documents in Hydrology, No 83), Paris.

Golybev, V. N., Frolov, A. D. (1998). Modelling the change in structure and mechanical properties in dry-snow densification to ice. Annals of Glaciol., 26, 45-50.

Gorsky, Yu. M., \& Gorskaya, N. I. (1970). Organizatcionno-informatcionnye mery dlya otcenki funktcionirova-niya geograficheskogo rayona kak metastabilnoy sistemy. Doklady Instituta geografii Sibiri i Dalynego Vostoka, 27, 17-28 (in Russian).

Gray, D. V., \& Male, D. H. (Eds.). (1981). Handbook of snow. Principle, processes, management \& use. Toronto, Canada, TC: Division of Hydrology, University of Saskatchewan, Saskatoon.

Grigoryev, D. P. (1965). Ontogeny of Minerals. Jerusalem, J: Izrael Program for Scientific Translations.

Grigoryev, D. P., \& Zhabin, A. G. (1975). Ontogeniya mineralov. Individy. Moskva, M.: Nauka (in Russian).

Harbaugh, J.W., and Bonham-Carter, G., (1970). Computer simulation in geology. New York-London-Sydney-Toronto, NYLST: Wiley-Intersience.

Honigman, B. (1958). Gleichgewichte- und Wachstumsformen von Kristallen. Darmstadt.

Kaempfer, Th. U., Sokratov, S. A., \& Schneebeli M. (2004). The effect of the structural evolution of snow on the heat transfer. Proc. of the 3th Intern. Symposium on two-phase flow modeling and experimentation. Edizi-oni ETS, Piza, 2, 715-730.

Kobayashi, T. (1957). Experimental researches on the snow crystal habit and growth by means of diffusion cloud chamber. J. Met. Soc. Japan, 75, 38-47.

Kolomyts, E. G. (1976). Structura snega i landshaftnaya indikatciya. Moskva, M.: Nauka (in Russian).

Kolomyts, E. G. (1977). Techniques for the crystal-morphological analysis of snow structure. Translate from the Russian by C. E. Bartelt. (2011). Birmensdorf, B,: Funds of the Swiss Federal Inst. for Forest, Snow and Landscape Research.

Kolomyts, E. G. (1984). A Crystal-morphological Atlas of Snow (A Handbook for Snow-Avalanche Station). Translate from the Russian by C.E. Bartelt. (1997). Birmensdorf, B.: Funds of the Swiss Federal Inst. for Forest, Snow and Landscape Research.

Lehning, M., Bartelt, P. B., Brown, R. L., \& Fierz, Ch. (2002). A physical SNOWPACK model for the Swiss avalanche warning: Part III: meteorological forcing, thin layer formation and evolution. Cold Reg. Sci. Technol., 35, 169-184. http://dx.doi.org/10.1016/S0165-232X(02)00072-1

Nakaya, U. (1954). Snow crystals: natural and artificial. Cambridge, C.: Harvard Univ. Press, MA.

Odum, E. P. (1983). Basic Ecology. Vol. 2. Philadephia - New York-Chicago, Ph-N-Y-Ch.: Saunders Col- lege Publishing.

Paulke, W. (1938). Practische Schnee- und Lawinenkunde. Berlin, B.: Verlag Julius Springer. 
Pielmeier, Chr. \& Schneebeli, M. (2003). Developments the stratigraphy of snow. Surv. Geophys., 24, 389-416. http://dx.doi.org/10.1023/B:GEOP.0000006073.25155.b0

Polozova, L. G. (1954). O kharakteristike kontinentalnosty klimata. Izvestiya Vsesoyuznogo Geogr. Ob-shchestva. 86(5), 412-422 (in Russian).

Rikhter, G. D. (1948). Roly snezhnogo pokrova v phyziko-geographycheskom protcesse. Trudy Instituta geographii AN SSSR. 40 (in Russian).

Rikhter, G. D. (1955). Ispolyzovanie snega v narodnom khozyaystve i zadachi ego izucheniya. Voprosy izucheniya snega i ispolyzovaniya ego v narodnom khozyaystve. Moskva, M.: Izdatelstvo AN SSSR (in Russian).

Rubinshtein, E. E. (1953). O vliyanii raspredeledniya okeanov i sushi na Zemnom share na temperaturu voz-dukha. Izvestiya Vsesoyuznogo Geogr. Obshchestv, 85(4), 373-381 (in Russian).

Schaefer, V. J., Klein, G. J., \& de Quervain M. R. (1954). The International Classification for Snow (with special reference to snow on the ground), 31. The Commission of Snow and Ice of the Internat. Assoc. of Hydrology. Associate Committee on soil and snow mechanics. National Research Council., Ottawa, Canada.

Seligman, G. (1936). Snow Structure and Ski Fields. London, L.: Macmillan and Co. Ltd.

Shafranovsky, I. I. (1968). Lektcii po kristallomorfologii. Moskva, M.: Vysshaya shkola (in Russian).

Shafrabovsky, I. I. (1974). Ocherki po mineralogicheskoy kristallografii. Leningrad, L.: Nedra (in Russian).

Sheftal, N. N. (1961). K voprosu o realnom kristalloobrazovanii. Rost kristallov, III, 9-21 (in Russian).

Sheftal, N. N. (1973). Gleichtgewichtsform und Form des idealen Einkristall. Kruistall und Technik., 8(1-3), 149-168. http://dx.doi.org/10.1002/crat.19730080115

Sheftal, N. N., \& Kolomyts, E. G. (1973). Evolutsiya konechnyh form rosta kristallov v zavisimosti ot vkhozhdeniya sredy v ih sostav. Acta phys. Acad. Sci., Hangar., 33(3-4), 335-351 (in Russian).

Shneebeli, M., \& Sokratov, S. A. (2004). Tomography of temperature gradient metamorphism of snow and associated changes in heat conductivity. Hydrological Processes, 18(18), 3655-3665. http://dx.doi.org/10.1002/hyp.5800

Shubnikov, A. V. (1975). Izbrannye trudy po kristallografii. Moskva, M.: Nauka (in Russian).

Shubnikov, A. V., \& Koptsik, V. A. (1972). Simmetriya v nauke i iskusstve. Moskva, M.: (in Russian).

Socratov, S. A. (2001). Parameters influencing the recrystallization rate of snow. Cold Reg. Sci. Technol., 33 (2-3), 263-274. http://dx.doi.org/10.1016/S0165-232X(01)00053-2

Sokratov, S. A., \& Barry, R. G. (2002). Intraseasonal variation in the thermoinsulation effect of snow cover on soil temperatures and energy balance. J. of Geophys. Research. Atmospheres, 107(D19), 4374. http://dx.doi.org/10.1029/2002JD001595

Sokratov, S. A., \& Troshkina, E. S. (2009). Rasvitie strukturno-stratigraphicheskih issledovany snezhnogo pokrova. Materialy glyatciologicheskih issledovaniy, 107, 103-109 (in Russian).

Sommerfeld, R. A., \& La Chapelle, E. R. (1970). The classification of snow metamorphism. J. Claciol., 9(55), 3-17.

Timofeev-Resovsky, N. V., Bovorontsov, N. N., \& Tyblokov, A. V. (1969). Kratky ocherk teorii evolyutsii. Moskva, M.: Nauka (in Russian).

Tushinsky, G. K., Gusykova, E. F., \& Gubareva, V. D. (1953). Perecristallizatsiya snega i vozniknovenie lavin. Moskva, M.: Izdatelstvo MGU, 1953 (in Russian).

Vernadsky, V. I. (1965). Himichesky sostav biosphery Semli i ee okruzheniya. Moskva, M.: Nauka.

Watanabe, Z. (1980). Tensile strain and fracture of snow. J. Glaciol., 26(94), 255-262.

Yosida, Z. (1966). Surface structure of ice crystal and its equlibrium from. Inst. Low Temperat. Sci. Phys. Sci., Sapporo, 24, 1-19.

Yushkin, N. P. (1977). Teoriya i metody mineralogii. Leningrad, L.: Nauka (in Russian). 